\title{
Fridays of Revolution: Focal Days and Mass Protest in Egypt and Tunisia
}

\author{
Neil Ketchley and Christopher Barrie*
}

November 18, 2019

\begin{abstract}
Focal days of protest are increasingly common to episodes of revolutionary mobilization. This paper explores the significance of focal days in patterning sustained protest in Egypt and Tunisia from 2011 to 2012. In Egypt, resourcepoor activists exploited the confluence of worshippers on Fridays to mobilize mass transitory protest. This reliance on ritualized action hindered crosssectoral coordination and meant mass protest often failed to inflict a direct economic cost. In Tunisia, there was no focal day of protest, in large part due to the coordinating hand of trade unions. In consequence, mass protest was more likely to span multiple sites, sectors, and tactics. These results suggest that oppositions can sustain mass mobilization even absent organizational capacity, but a reliance on a focal day limits the potential of protest over a political transition. Supplementary analyses point to the applicability of our findings to a number of other Arab Spring countries.
\end{abstract}

*Both authors contributed equally. The research was funded by the John Fell OUP Research Fund. An earlier version of this paper was presented at the 2017 annual conferences of the American Political Science Association and the Social Science History Association, as well as to audiences at the American University in Cairo and King's College London. Steven Brooke, Jalal Imran, and Kevin Mazur, as well as three anonymous reviewers, gave helpful comments and suggestions. Neil Ketchley (neil.ketchley@stv.uio.no) is Associate Professor of Political Science in the Department of Political Science, University of Oslo. Christopher Barrie (christopher.barrie@nuffield.ox.ac.uk) is Postdoctoral Prize Research Fellow in Sociology at Nuffield College, University of Oxford. The data and code required to reproduce the statistical analyses can be downloaded from https://doi.org/10.7910/DVN/CLIGCI. 


\section{Introduction}

From the Monday sit-ins in Leipzig against the German Democratic Republic to Friday demonstrations in Syria agitating for the downfall of the Baathist regime, focal days of protest have emerged as important tools for assembling large crowds of citizens in contexts of authoritarianism. In such cases, a focal day appears to solve a collective action problem in the absence of an organized opposition. The logic is intuitive. In authoritarian regimes, opposition forces are rarely able to organize openly, and so struggle to coordinate mass protest or even communicate a message of resistance to broad publics. Focal days of protest, which invariably fall on public holidays or some other occasion that naturally involves the gathering of large numbers of citizens, circumvent this problem by providing the date and time setting function of protest usually performed by social movements and opposition groups. This dynamic has been highlighted by both rational choice theorists and scholars of revolution as integral to the formation of revolutionary bandwagons, as opposition forces are able to exploit commonplace routines of social interaction to draw ordinary citizens into mass mobilization. In consequence, authoritarian regimes have securitized national holidays and other symbolic occasions, as they look to obviate popular unrest.

While the power of focal days of mobilization is increasingly recognized by dictators and political scientists alike, their impact on patterning prolonged periods of protest has evaded systematic empirical investigation. This reflects a more general shortcoming in the literature on social movements and collective protest: while significant attention has been paid to the temporal fluctuations of mass protest in mature Western democracies - where social movements and not focal days are an established feature of the contentious landscape - far less is known about how sustained waves of protest unfold in settings where movements either lack organizational capacity or are entirely absent. This has particular implications for how we explain the trajectory and fate of recent democratic breakthroughs, which are frequently led by loosely-organized "negative coalitions" (Beissinger 2013) and rely 
on focal days to sustain street-level mobilization. In order to begin addressing this gap, we assess the relative significance and impact of a focal day of protest in Egypt and Tunisia. To carry out our analysis, we draw on two original catalogues of protest events totalling over 9,000 events derived from Arabic- and French-language news and social media. We begin by tracing the emergence of Friday as a focal day of protest in Egypt during the 25th January Revolution in 2011. We then scrutinize the temporal patterning of protest in Tunisia during the same period, to discern if comparable dynamics were present in a geographically and culturally proximate context. Finally, we compare how a focal day of protest influenced the sectors, repertoires, and locations of protest in these two cases.

Our results suggest that the reliance of organizationally weak actors on a focal day that falls on a weekend can simultaneously enable and segment contentious collective action. While potentially large, Friday protest is less likely to involve groups and movements from multiple sectors, less likely to endure, and less likely to span multiple locales. Absent organizations capable of dictating the rhythm of protest, activists in Egypt exploited the focal qualities of Fridays to amass large numbers of people in transitory protests that left places of worship for public spaces. By contrast, Egyptian workers and student groups were much less likely to mobilize on Fridays, with workplaces and university campuses also seeing significantly less protest on Fridays. In consequence, days of mass protest inflicted little direct economic cost, undermined the possibilities of cross-sectoral mobilization, and gave rise to a repertoire that was comparatively easy to police. In Tunisia, there was no single focal day of action, in large part due to the coordinating role of organized labor. In that context, the transitional regime often faced successive days of protest that spanned multiple sites, sectors, and tactics. Supplementary analyses point to the application of our results to numerous other cases in the Middle East and North Africa (MENA). Taken together, these findings point to a hitherto unappreciated dynamic: in contexts of political disorganization, the "when" of protest can powerfully influence the "who," the "how," and the "where" of mass mobilization. 


\section{Focal days of protest}

The "who" in protest research refers almost invariably to organized movements or movement leaders. Corollary of this, the "how" and the "where" of protest are assumed to flow from the decisions of organizations. This assumption is found most obviously in studies aligned with the resource mobilization approach, which sees organization as among the most important resources available to potential protesters (McCarthy and Zald 1977). The guiding assumption of this literature could be summarized as: "the more organization, the better the prospects for mobilization and success" (Clemens and Minkoff 2004: 155). The importance of organizational resources has been identified in shaping movement outcomes (Clemens 1993), on levels of protest nationally and cross-nationally (Dalton et al. 2010), on movement emergence and continuity (Verta 1989), the diffusion and decline of protest (Minkoff 1997), the brokering of common fronts through processes of "mesomobilization" (Gerhards and Rucht 1992), and the facilitation of large-scale non-local protest (Fisher et al. 2005).

A second literature keys the patterning of mass mobilization to developments in the political process. When it comes to the timing of protest, the emphasis of much of this scholarship is on responsiveness to shifts in political opportunity structure, both discursive and institutional, and the role of social movement organizations in perceiving and acting on such openings (Koopmans and Olzak 2004; Tarrow 2011). Most importantly, scholars argue, activists react strategically to changing opportunity structures, employing adaptive tactics in the face of repression or political openings, and utilizing alternative repertoires of action in alternative locales to respond to changes in the political environment (Lichbach 1995). By way of example, movement leaders may elect to call strikes, over public (and more exposed) demonstrations, in the wake of repression (Francisco 2004). Relatedly, movements might innovate and employ new tactics in the wake of defeat (McCammon 2012).

The majority of this research pertains to Western liberal-democratic regimes a limitation acknowledged by the originators of the resource mobilization approach 
(Zald and McCarthy 2002: 150) - and exhibits a clearly "movement-centric" bias (McAdam and Boudet 2012). By comparison, we know little of the determinants of mass mobilization in non-democratic contexts where organizational weakness predominates, and where freedom of association and assembly are curtailed, and so social movements are either heavily circumscribed or entirely repressed. Here, the "who" of protest is likely not to be an organized movement but instead disorganized and fragmented coalitions operating in semi-legality. As Beissinger (2013) notes, contemporary "urban civic revolutions" frequently lack internal coherence as a campaign and, after achieving the ouster of an authoritarian incumbent, are often hamstrung by the absence of any coherent organizational basis.

How then do disparate actors manage to overcome their organizational weakness and continue to challenge regimes? A key argument is that in conditions of organizational weakness, mass mobilization is aided by "focal point" solutions (Schelling 1960). In the case of the "Colour Revolutions" of the early- to mid-2000s, these were provided in part by stolen elections (Tucker 2007). Ritualized action, Pfaff and Yang (2001) suggest, can also help overcome collective action problems in such settings. Pointing to the state-socialist regimes in Eastern Europe and China in 1989, they show how protest can be mobilized in the absence of organizational resources familiar to us from the resource mobilization paradigm. Indeed, previous episodes of mass mobilization, notably the protests in Leipzig that led to the fall of the Berlin Wall, have demonstrated the centrality of rituals as focal point solutions to coordination problems (Opp and Gern 1993; Lohmann 1994). The Monday protests in Leipzig relied on the institution of "peace prayers" held every Monday from 5-6 P.M. in churches in the surrounding area that provided a definite time and place for would-be protesters to congregate and an "institutional incentive" (Opp and Gern 1993) to participate. So too, during the Iranian Revolution, ritualized religious action came to perform a date-setting function for protest as the forty-day mourning cycle served to structure patterns of contention (Rasler 1996). More contemporaneously, Friday protests were a key feature of the Arab Spring, as citizens 
exploited their periodic confluence in places of worship to stage large demonstrations in public spaces (Ketchley 2017). Crucially, in these instances, the "who" of protest - in the form of organization leaders or movements - was no longer the sole arbiter of the coordinates of contentious collective action. Instead, where organizational weakness abounds, the "when" - in the form of a calendar of ritualized action appears to powerfully influence who might participate.

What are the observable implications of a reliance on focal days? Here, we take lessons from the theoretical literature on ritualized action and argue that this reliance will produce systematic regularities in the tactics and locations of protest. The "common knowledge" (Chwe 2001) required for such action is a product of the unchanging, predictable, iterative nature of rituals themselves and the "repertoire of recognized practices" (Pfaff and Yang 2001: 556) of which they are formed. In consequence, we should expect to see a lack of adaptive tactical or geographical variation written into the functioning of ritualized contentious action. When these rituals follow a regular temporal rhythm, we might then expect to see systematic regularities in the weekly calendar of protest. By implication, the types of protest should be significantly distinct from those observed on other days of the week where, in the absence of ritualized action, protest can be expected to exhibit a more stochastic rhythm. When it comes to the specific types of protest we can expect to see on these days, one of the most common forms of ritualized contentious action involves the massing of large numbers of individuals on given days in focal public spaces for the staging of public demonstrations (Schock 2005; Beissinger 2013). As we will go on to detail, the ritualized recourse to this mode of protest may plausibly undermine the viability of protest campaigns.

An overarching hypothesis arises from the above discussion. We expect focal points to predominate in contexts of weakness; in the absence of organizations, activists and unaffiliated contentious actors will rely on focal days to launch protest. To the extent that this hypothesis finds support, an observable implication is that a ritual reliance on these focal point solutions will have consequences for who protests 
and how protest is conducted: what we refer to as the "who", the "how", and the "where" of mass mobilization. Specifically, we expect that focal days will exhibit systematic regularities in the participants, tactics and locales of protest.

\section{Mass mobilization in Egypt and Tunisia}

We now explore these concerns as they relate to the wave of mass protest that unfolded in Egypt and Tunisia during the Arab Spring and its aftermath. The Egyptian and Tunisian cases are notable for witnessing relatively brief episodes of mass mobilization within short succession of one another, with both episodes culminating in the ousting of a seemingly well-entrenched authoritarian (Gunning and Baron 2013; Hmed 2015; Ketchley 2017). Both countries also saw sustained protest during post-breakthrough democratic transitions. Being Sunni-majority countries located in North Africa with long histories of Islamist activism, they also share broadly comparable religious and socio-cultural profiles. Nationally representative surveys fielded during our analysis period suggest that sizeable proportions of both populations regularly attended mosques and engaged in daily religious practices, and this allows us to hold constant the relative availability of Islamic associational activities in patterning contentious collective action. ${ }^{1}$

\footnotetext{
${ }^{1}$ Note that self-reported religiosity and mosque attendance is typically higher in Egypt than in Tunisia, although this depends on the survey. In Wave II of the Arab Barometer, fully 94 percent of males in Egypt reported attending Friday prayer "always" or "most of the time," while 83 percent said that they prayed daily. In Tunisia, 52 percent of males went to Friday prayer "always" or "most of the time," and 60 percent of respondents reported praying daily. Similarly, a 2012 Pew survey found that 70 percent of Egyptians went to mosques at least once a week (including Friday prayer), while in Tunisia 54 percent did the same. However, in Wave VI of the World Values Survey, this is reversed: 40 percent of Egyptian Muslims reported attending religious services "once/more a week," compared to 45 percent of Tunisians. Also, in the 2012 Pew poll, 53 percent of Egyptian Muslims claimed to pray all five prayers daily, compared to 63 percent of Tunisians. For our purposes, it is sufficient that, even where levels of religiosity
} 


\subsection{Sources}

Our principal data sources for this research are two event catalogues derived from Egyptian and Tunisian news media that captured protest from December 2010 to January 2012. To identify protest events, we employed Horn and Tilly's (1988) definition of contentious gatherings as "occasions on which at least ten or more persons assembled in a publicly-accessible place and either by word or deed made claims that would, if realized, affect the interests of some person or group outside their own number." Events were coded, inter alia, for date of occurrence, repertoire (e.g. demonstration, march, occupation, sit-in, strike), participation, and organizer. ${ }^{2}$. The principal source for the Egyptian catalogue is al-Masry al-Youm, while two further newspapers — al-Dostor and al-Shorouk — were used during periods of particularly intense mobilization in order to guard against potential "news hole" effects (Oliver and Maney 2000).

The same coding conventions were used for identifying protest events in Tunisia. Here, the principal news source used was al-Chourouk. This newspaper was archived by the online newspaper aggregator and archiving tool turess.com. ${ }^{3}$ For the twentynine day period of revolutionary mobilization from December 17 2010-14 January 2011, national print news media did not report on protest until the closing stages of the uprising. For this period, we elected to use several archived Facebook pages created for the purposes of reporting on protest during the media blackout, alongside international news media, and the multiple daily written protest reports produced by Tunisian radio station Kalima Tunis, which were also archived on turess.com. Full details of sources for the Tunisia event catalogue can be found in the Appendix.

For the purposes of comparison, we confine attention to the episodes of mass differ, a threshold level of religious activity enabling of regular protest outside places of worship is satisfied in both cases.

${ }^{2}$ The codebook is provided in the Appendix together with details of the coding conventions when protest size was not reported.

${ }^{3}$ For some days, al-Chorouk was not available. On these occasions, we used instead a combination of La Presse and the Agence Tunis Afrique Presse. 
uprising that led to a democratic breakthrough in both countries, and the first year of the subsequent democratic transition. In total, for the period we analyze, we have records of 4,925 protest events in Egypt and 4,828 protest events in Tunisia.

\section{Egypt, 2011-2012}

The ousting of President Husni Mubarak on 11 February 2011 following eighteen days of disorderly and energetic protest unleashed an unprecedented wave of mobilization in Egypt. The scale of this mobilization is all the more noteworthy for the absence of well-resourced opposition movements. ${ }^{4}$ In what follows, we give an account of the organizational landscape in Egypt during this period, before considering the emergence of Fridays as a focal day of protest during the 25th January Revolution and how it came to pattern contention in the post-Mubarak transition. We then compare Egypt to Tunisia, to establish whether a reliance on a focal day of protest travels to an analogous socio-political context where social movement organizations are comparatively better resourced.

\subsection{Protest without movement}

Following Mubarak's resignation on 11 February 2011, the Muslim Brotherhood, Egypt's most significant social movement, demobilized to focus on securing a place in a newly elected parliament (see Ketchley 2017: ch.4). Figure 1 charts Muslim Brother mobilization as a percentage of all protest events involving social movements and activists between 2011 and 2012. While the Brotherhood did return to the streets periodically to protest backsliding by the transitional military government, as well as to raise other local grievances, they were noticeably absent from the

\footnotetext{
${ }^{4}$ This is not to deny the existence of prehistories of mobilization on the part of workers and activists in the decade prior to the 2011 Revolution. Workers, as well as groups such as Kefaya and April 6, did lead sustained protests in the years leading up to 2011. However, the coordinating capacity of such groups was low (see Clarke 2014).
} 


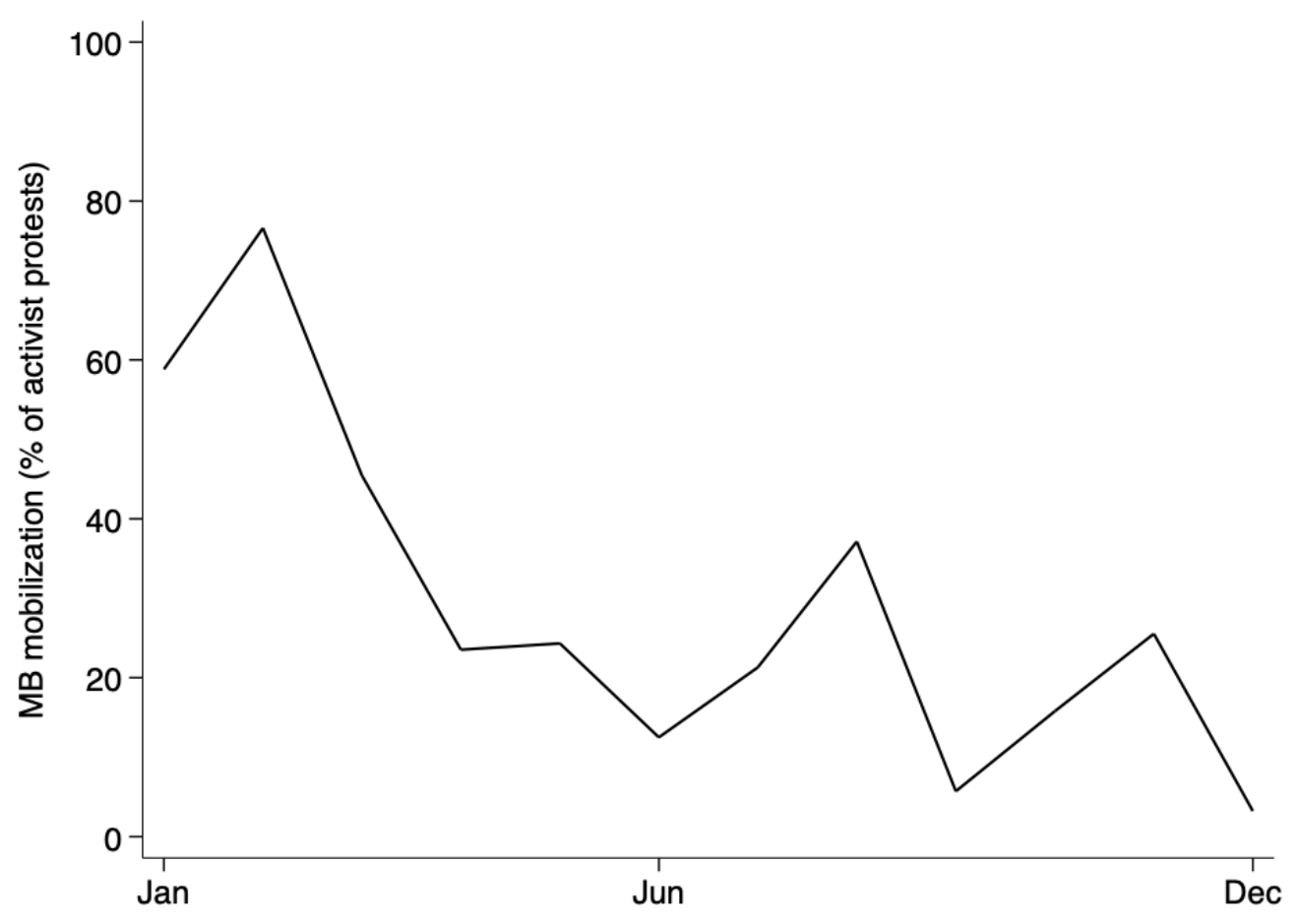

Figure 1: Muslim Brotherhood mobilization as a percentage of activist protests, 2011-2012

iconic venue of Midan al-Tahrir, as well as the large Friday protests called for by other activist groups. Instead, the vast majority of activist-led protests during this period were called by secular movements and groups with small memberships and only a titular organizational presence nationwide. As Abdelrahman (2013) notes, these non-Islamist forces often took the form of informal networks with no branch infrastructure or organized cadre. The organizational weakness of these actors is all the more apparent when we consider their performance in elections held after Egypt's democratic breakthrough, when secular, pro-revolutionary candidates failed to compete with the electoral machines commanded by the country's Islamist movements (Masoud 2014).

The Muslim Brotherhood's' absence from street-level mobilization following the 25th January Revolution poses an interesting puzzle. If theories of resource mobilization and political process assume that collective protest unfolds under the direction of activists and social movements, who have the organizational resources to respond to political opportunities and frame grievances, this leaves unexplained variation in the occurrence of mass protest in the post-Mubarak transition. Against this back- 


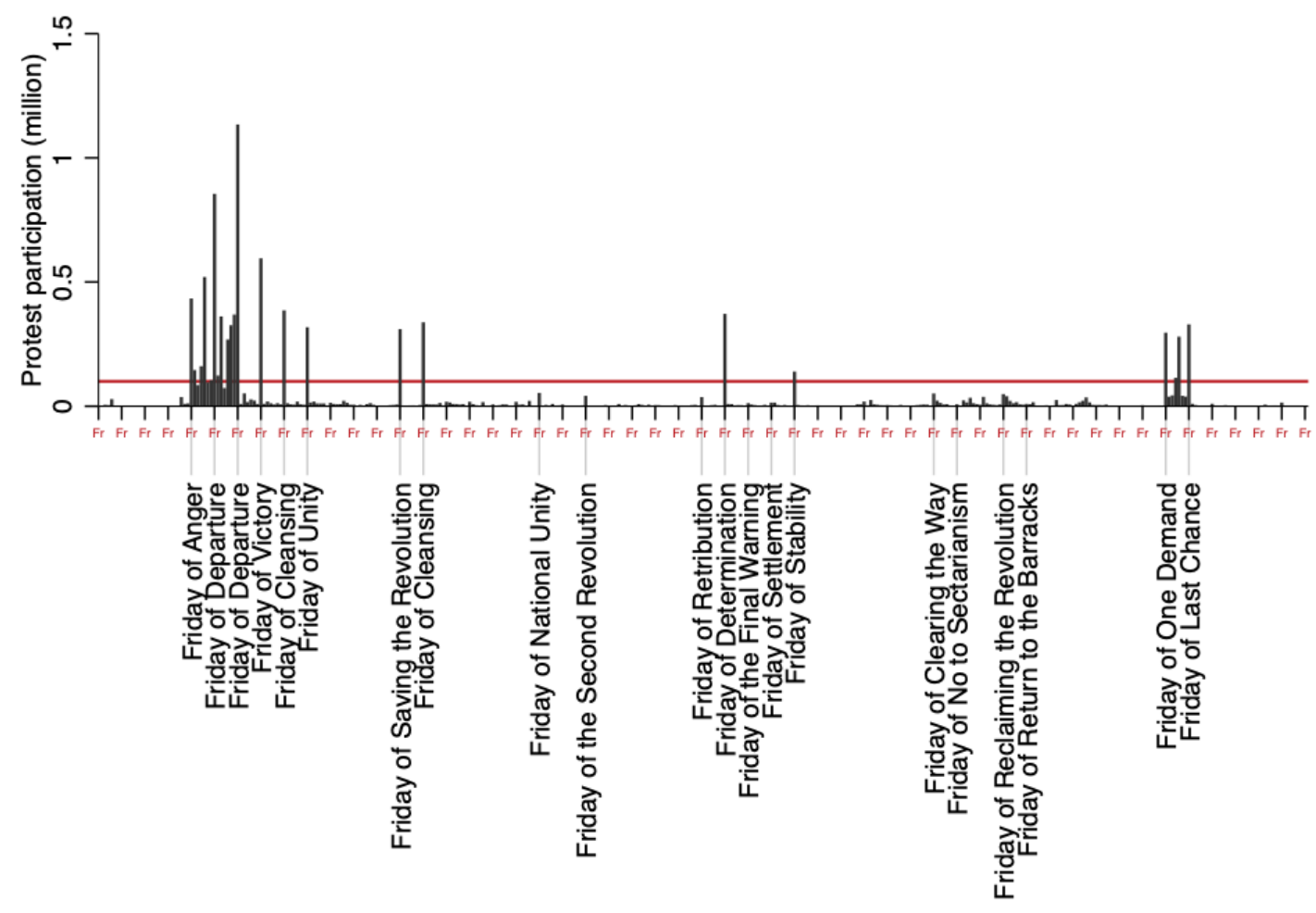

Figure 2: Protest participation in Egypt, 2011-2012.

Notes: The red y-line marks 100,000 protestors; "Fr" marks Friday.

drop, we consider the role that Fridays played in the timing of contention over this period.

\subsection{Fridays of revolution}

The importance of Fridays in patterning protest participation in Egypt is well illustrated using event data. Figure 2 shows daily protest participation between 2011 and 2012. During this period, mass mobilization (defined as $\geq 100,000$ protestors mobilizing on one day) occurred on 23 occasions: 12 of these were Fridays (52 percent). The association between Fridays and mass mobilization is even more pronounced in the post-Mubarak transition. Excluding the eighteen days of the 25th January Revolution, there were 11 days of mass protest in the year of Egypt's democratic breakthrough: 9 of these occurred on a Friday (82 percent). These protests did not occur spontaneously (see Gunning and Baron 2013; Ketchley 2017). Rather, they were typically called for in advance by secular activists and given names that were pregnant with revolutionary symbolism, e.g. the "Friday of Unity," the "Friday of 

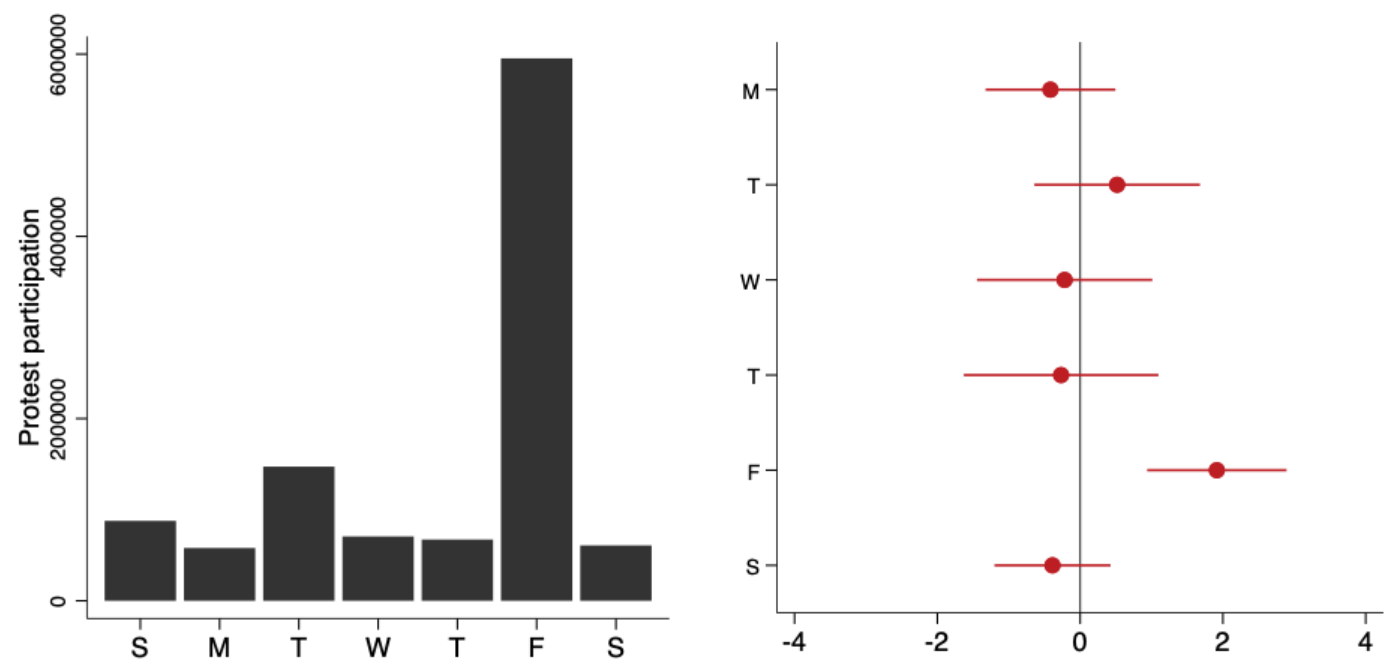

Figure 3: (Left) Protest participation by day of the week, 2011-2012; (Right) negative binomial regression of daily protest participation between 2011-2012 with Sunday as reference category.

the Last Chance," the "Friday of Reclaiming the Revolution," and so forth. This followed a repertoire fashioned during the first days of 25th January Revolution when opposition forces looked to mobilize mass protest on 28 January, dubbed the "Friday of Anger." On 27 January, the Mubarak regime had cut off access to internet and mobile phone services in a bid to demobilize anti-regime opposition. With few other means to coordinate mass protest, activists waited outside of mosques to rally crowds following the conclusion of prayer (see Gunning and Baron 2013: ch.6). The Muslim Brotherhood belatedly announced that they would also participate in these protests. The plan was a success: large crowds moved from mosques and converged on squares and main roads across the country. Once the efficacy of this repertoire was established, resource poor activists would consistently turn to the focal qualities of Friday protest to sustain revolutionary momentum in the post-Mubarak period.

Event data allows us to evidence this phenomenon systematically. Figure 3 sums participation in protests held between 2011 and 2012 by the day of the week. As our analysis reveals, more Egyptians protested on Friday than on any other day of the week. A pairwise comparison of average daily protest sizes between January 2011 and January 2012 suggests that protest participation on Fridays was three times larger than the daily average $(\mathrm{p}<.001)$. This test assumes equal variance in the residuals of our count data, and so we repeat our analysis using a Kruskal-Wallis 

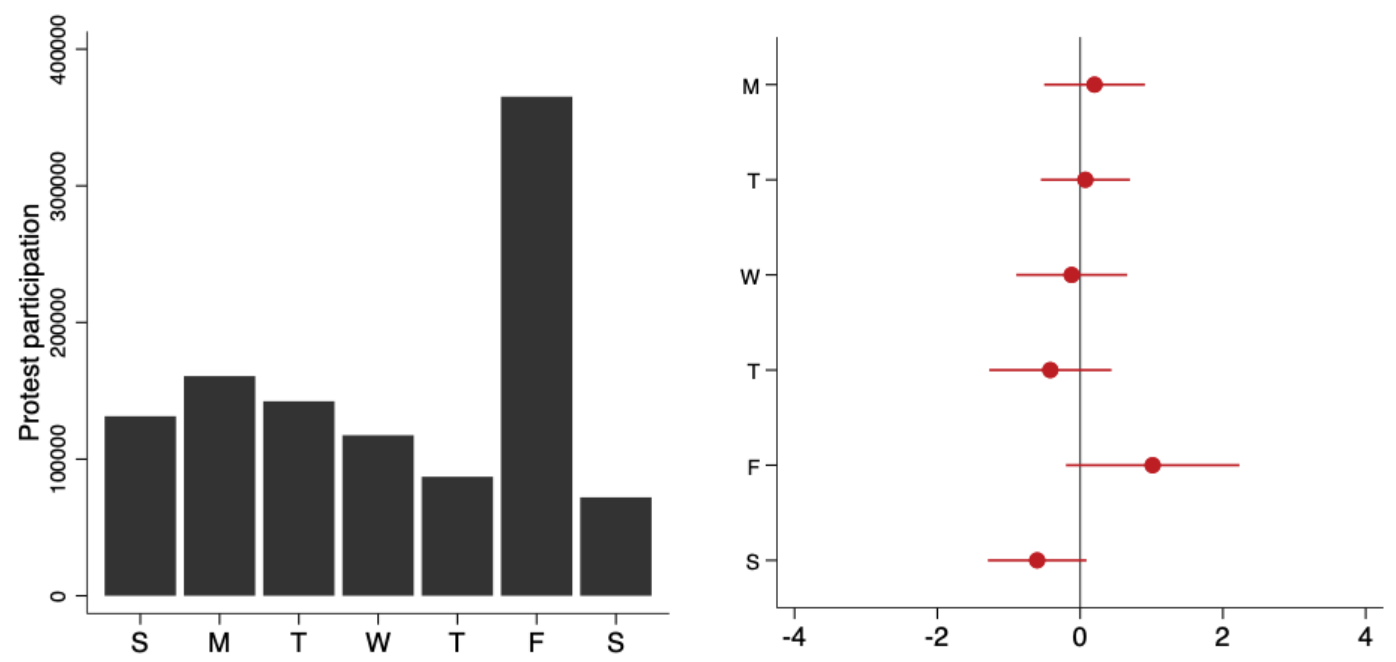

Figure 4: (Left) Protest participation by day of the week, 2008-2010; (Right) negative binomial regression of daily protest participation between 2008-2010 with Sunday as reference category.

test, a non-parametric alternative. The results are substantively identical: protest participation on Fridays stochastically dominates participation on other days of the week $(\mathrm{p}<.01)$. Setting Sunday as the reference category, negative binomial regression (shown in Figure 3), also suggests that Friday exerted a large and substantive effect on daily protest participation during this period $(\mathrm{p}<.001)$.

Interestingly, this patterning does not appear to predate the 25th January Revolution. Figure 4 considers the temporal patterning of protest participation in Egypt between 2008 and 2010 using event data collected by Gunning and Baron (2013). This data derives from the same Egyptian newspaper as our own event catalogue, making it ideally suited for a within-case across-time comparison. When aggregating protest participation to the day of the week (Sunday-Saturday), the bar graph appears to suggest that protest on Fridays was larger than on other days. However, this piece of evidence alone is misleading, as it does not take into account the large number of Fridays that saw small or zero protest. Indeed, when analyzed as part of a daily time series over several years, negative binomial regression, shown in the coefficient plot, suggests that protest participation on Friday was not statistically significantly larger than on protests held at the beginning of the working week. In other words, the ostensible Friday effect seen in the bar graph is attributable to a small number of large protests held on Fridays; on average, however, Friday 
protests were actually comparable to those held on Sundays. This makes sense when we consider the "who" of protest during this period. In the years before the 25th January Revolution, the majority of protests in Egypt were launched by workers in the context of employment disputes (25 percent), university students mobilizing on campuses (20 percent), or involved the country's largest social movement, the Muslim Brotherhood (21 percent). For those actors, Fridays held less significance, either because they had the organizational capacity to mobilize large numbers during the working week, or because workplaces and campuses became unavailable during the weekend. Taken together, the periodic amassing of diverse constituencies of protesters on focal Fridays appears to be an inheritance of the revolutionary conjuncture.

\section{Tunisia, 2010-2011}

Crucially, the significance of Friday protests in shaping the trajectories of streetlevel mobilization in Egypt is not simply a function of Islamic religious practice. Here, a comparison with contentious collective action in the year of the Tunisian Revolution against Ben Ali is illuminating. As previously noted, Wave II of the Arab Barometer (2011) finds that 52 percent of male Tunisians attended Friday prayers "always" or "most of the time." This translates into millions of individuals who routinely congregated at mosques on Fridays, and so suggests that Friday was available as a focal point solution in Tunisia during our analysis period. To put this figure into perspective, we can look at another former French colony in North Africa with a similarly fraught secular-Islamist cleavage: Algeria. Wave II of the Arab Barometer finds that 59 percent of male Algerians reported attending Friday prayers "always" or "most of the time." As we know, Fridays in Algeria have since gone on to function as a focal day of protest against the ossified regime of Abdelaziz Bouteflika, with participants even coining their own verb for protesting on a Friday: "vendredire" (see Jadaliyya June 13, 2019). If the focal qualities of Friday in shaping mobilization are culturally pre-determined, we might thus expect 
that protest participation in Tunisia would follow the same patterning. Figure 5 draws on our catalogue of Tunisian protest events. We repeat the analyses carried out above. Note that in Tunisia the working week runs from Monday to Friday, and so we set the reference category to Monday. The results are revealing. Negative binomial regression suggests that in Tunisia the scale of protest participation was no greater on Friday than on other days of the working week. Instead, we see a trend opposite to that witnessed in Egypt: compared to the first day of the working week, weekends see significantly lower levels of protest participation.

The absence of Friday as a focal day of protest is also apparent when examining the distribution of mass mobilization during the year of the Tunisian Revolution. In this period, there were 5 days of mass protest (defined as $\geq 100,000$ protestors taking to the streets on one day) - only 1 of these days fell on a Friday (20 percent). Confining attention to the post-Ben Ali transition, there were only 2 days of mass protest - neither of these fell on a Friday. Of course, this seeming absence of a focal day of mobilization may be attributable to Tunisia's considerably smaller population. In 2011, the population of Tunisia was 10.65 million, while in the same year the population of Egypt was 83.78 million. Thus, we might reasonably conclude that 100,000 protestors ( 1 percent of the population of Tunisia) is not a valid measure for comparison. To take into account Tunisia's smaller population, we also looked at days in which 10,000 protestors or more mobilized. Again, event data suggests that Friday did not function as a focal day of mass protest - of the 26 days when over 10,000 Tunisians took to the streets, only 4 fell on a Friday (15 percent). ${ }^{5}$ Crucially, no other day singularly predicts an increase in protest, indicating that Tunisians did not rely on a focal day to coordinate street-level mobilization.

What explains this divergence from the Egyptian case? Following our argument, and the broader literature on the role of resource-rich movements in coordinating mobilization, one obvious axis of variation relates to the date setting function

\footnotetext{
${ }_{5}^{5}$ In Appendix Table A1 we estimate coefficient differences in Friday protest participation in Egypt and Tunisia.
} 

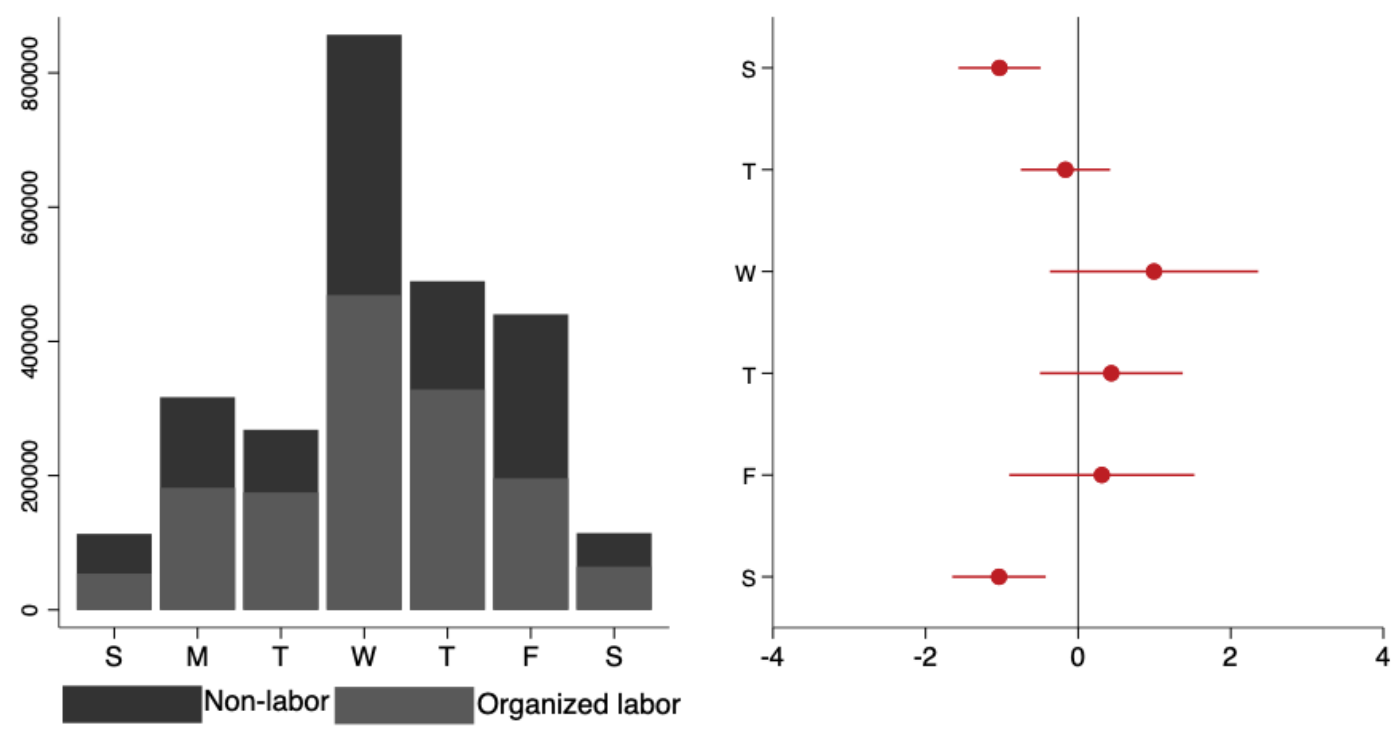

Figure 5: (Left) Protest participation by day of the week, December 2010 - December 2011; (Right) negative binomial regression of daily protest participation between 2010-2011 with Monday as reference category.

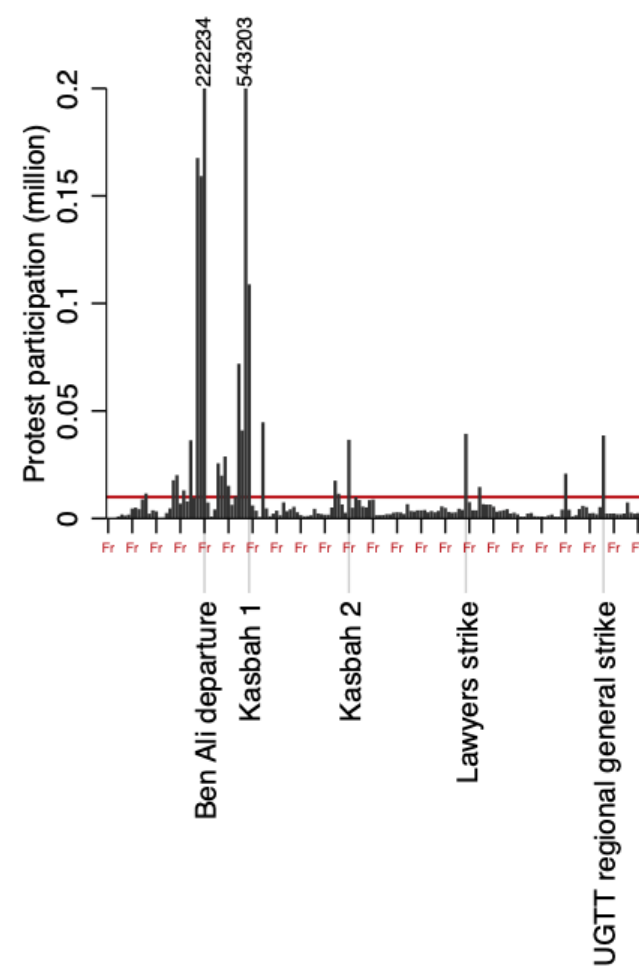

Figure 6: Protest participation in Tunisia, 2010-2012.

Note: The red y-line marks 10,000 protestors; "Fr" marks Friday. 
of Tunisia's trade unions. In Tunisia, the Union Générale Tunisienne du Travail (UGTT) played a leading role in the anti-Ben Ali mobilization. The UGTT is the country's largest trade union and can claim a membership of over 500,000 members (5 percent of Tunisia's adult population) as well as an organizational presence in each of Tunisia's twenty-four governorates. Figure 5 shows the capacity of organized labour for coordinating mobilization: most protestors mobilized during the working week alongside workers, often in response to general strikes called by the UGTT. Crucially, unlike in the Egyptian case where the Muslim Brotherhood demobilized to focus on elections, the UGTT did not withdraw from street-level mobilization following Ben Ali's ousting. In other words, the Tunisian case conforms to the expectations of the literature on resource mobilization and protest cycles: a focal day of protest played no significant mobilizing role in a context of organized political opposition.

A particular episode, in the immediate aftermath of Ben Ali's departure, is illustrative of the powerful role of organized trade unions in coordinating protest action. While initially a participant in the "National Unity" government of Mohammed Ghannouchi, the ministers put forward by the UGTT for this coalition government would resign just four days later, on January 18, under pressure from the street and the UGTT's membership base. In the following week and a half, numerous districts of Tunisia saw daily protest marches against the interim government, which were either organized by, or received the support of, the UGTT. The Tunisian Teachers Union took strike action from January 24 explicitly demanding the dissolution of the Ghannouchi-led government, and the UGTT would give its support to the simultaneous occupation of Kasbah Square in Tunisia's capital. This accumulating wave of street-level contention would culminate in a series of regional general strikes and large protest marches, from January 26-27, in all of El-Kef, Jendouba, Kairouan, Nabeul, Sidi Bouzid, Sfax, and Sousse led by the UGTT. The old regime holdovers in the Ghannouchi-led government resigned on 27 January. Figure 6 gives an idea of the size and timing of these protests. Tellingly, over the course of 2011, 
Tunisia saw no named days of protest nor any obvious regularity to the timing of mass contention outside of the revolutionary period. Here, then, we see play out the counterfactual scenario absent in Egypt. Armed with a powerful institutional actor broadly supportive of the demands of the street, contention in Tunisia did not rely on the ritual weekly gathering of loosely affiliated actors on a focal day of protest. Rather, protest action was immediately responsive to the unfolding political process and could rely on the support of organizations with the capacity to diversify the fronts on which, and means by which, protest was conducted.

\section{$6 \quad$ Focality and protest in Egypt and Tunisia}

Having established that there was a focal day of protest in Egypt and not in Tunisia, we now look to explain how a focal day patterned the cycle of protest in the postMubarak transition. Here, we are interested in examining how a focal point impacts the coordinates of contentious collective action in the absence of an organized opposition, and so we analyze how Friday protests shaped the "who," the "how," and the "where" of mass mobilization following Egypt's revolutionary breakthrough. The conclusion of parliamentary elections in January 2012 signalled a profound shift in political opportunities in Egypt, and so we concentrate on the first year of the post-Mubarak transition, when Egypt's activist scene was at its most energetic (see Ketchley 2017: ch.4). To establish that this dynamic was rooted in the organizational weakness that characterized the political field in Egypt, we simultaneously analyze how these differing characteristics of protest played out in Tunisia. If our argument holds, no single day should predict an upsurge in protest in the Tunisian case.

\subsection{Analytical strategy}

Our dependent variables are counts of protestor participation. The unit of analysis is the national protest day. Rather than test variables for every movement, place or 
tactic, we abstract those characteristics that we anticipate will be most affected by having a focal day of protest. Our expectation is that who protests varies depending on the day of the week, and so we analyze participation in protests launched by activists, worker groups, university students, and local residents. Following the social movements literature, the "who" refers specifically to protest groups and not participants more generally. While individual participation identities are no doubt of interest, these are difficult to ascertain, especially in the context of mass mobilization events. We are next interested in how temporality conditions where people protest. To explore this, we code variables for protest participation in workplaces (factories, companies, government offices and public utilities), university campuses, public spaces (main roads and public squares), and places of worship (mosques and churches). Finally, we expect that the day of the week will influence how protestors mobilize. Thus, variables are coded for the number of protestors engaging in disruptive repertoires (violent attacks, blockades, and sit-ins), economic protests (strikes), transitory protests (marches and demonstrations), and static protests (protest occupations).

As is common to quantitative analyses of protest, our counts of protest participation show pronounced overdispersion, and so negative binomial regression is preferred. ${ }^{6}$ Negative binomial regression models protest participation $\mu$ at date $t$ as a function of day of the week by:

$$
\tilde{u}_{t}=\exp \left(\beta_{0}+\beta_{1} X_{1}\right) \delta
$$

where $X_{1}$ is a categorical variable measuring day of the week with the reference category set to the first day of the working week for each country (i.e., Sunday for Egypt, Monday for Tunisia), and $\delta$ is the error term drawn from a gamma distribution with variance $\alpha$. As our data structure is a time series, we use Newey-

\footnotetext{
${ }^{6}$ Residual plots of daily protest participation can be found in Appendix Figures A.3 and A.4. In all cases, goodness of fit tests indicate negative binomial regression should be preferred to a Poisson model.
} 
West standard errors to correct for serial autocorrelation.

\subsection{Results}

We present regression results graphically with coefficients expressed as point estimates located on their 95 percent confidence intervals (the full regression outputs can be found in Appendix Tables A1-6). Each dependent variable is modelled separately, with models grouped by sector, location and repertoire.

We begin with protest participation by sector. Figure 7 analyses participation in protest events organized by workers, student groups, local residents, and activists in Egypt. Fridays have a significant and substantive effect on the patterning of sectoral mobilization. On average, participation in protest events organized by activists was much larger on Fridays than on Sundays $(\mathrm{p}<.001)$. We find the inverse pattern for participation in protests involving worker groups and student organizations. Friday has no discernible effect on participation in local residents' protests. Figure 7 suggests that a very different pattern obtained in Tunisia, where larger protests were more likely to take place during the working week. There is some evidence that protest launched by workers was more likely to fall in the middle part of the week (Wednesdays and Thursdays), while protest organized by local residents and students was slightly less likely on Tuesdays, Wednesdays, and Fridays. Importantly, though, there is no one single day on which systematic differences in the sectors engaging in protest are concentrated. What is more, in direct opposition to the trend observed in Egypt, the only days on which multiple sectors exhibit a reduced likelihood of organizing protest is on the weekend when workplaces are closed. We thus have further confirmation of the more general trend in post-revolutionary Tunisian protest identified above: organized labour is central to the trajectories of mass mobilization over this period, and no focal day of protest obtained.

Turning to how people protested, results shown in Figure 8 suggest that Egyptians were much more likely to engage in large transitory protests on Fridays. However, protestors were significantly less likely to join protests that inflicted a direct 
(a) Egypt

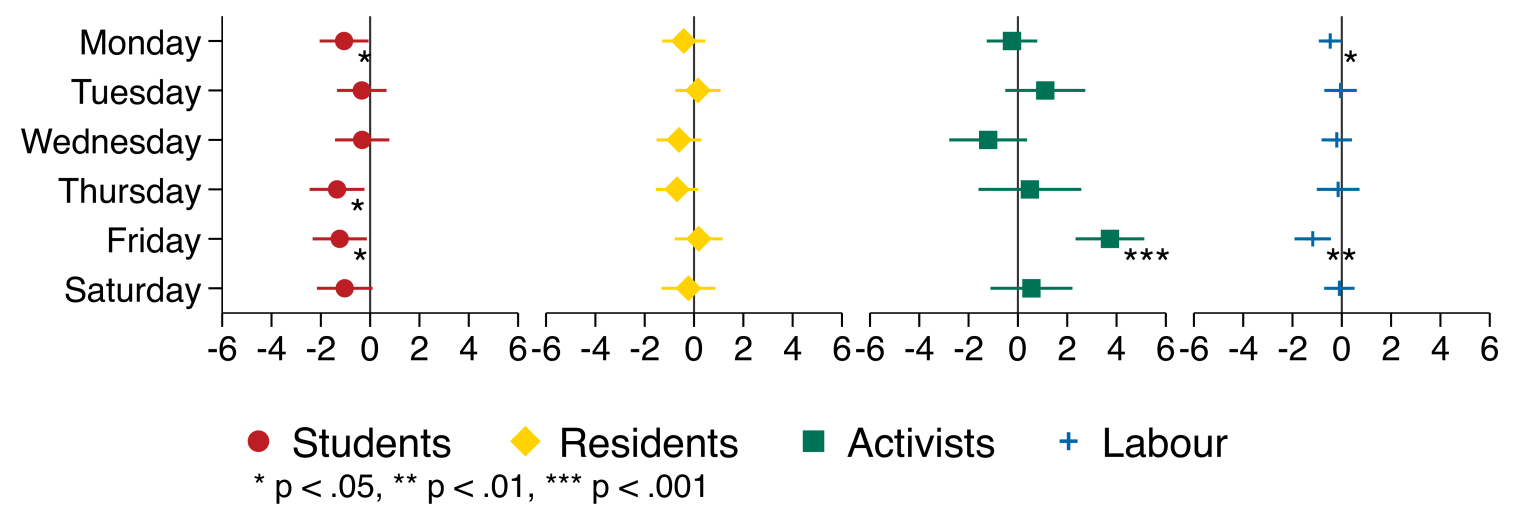

(b) Tunisia

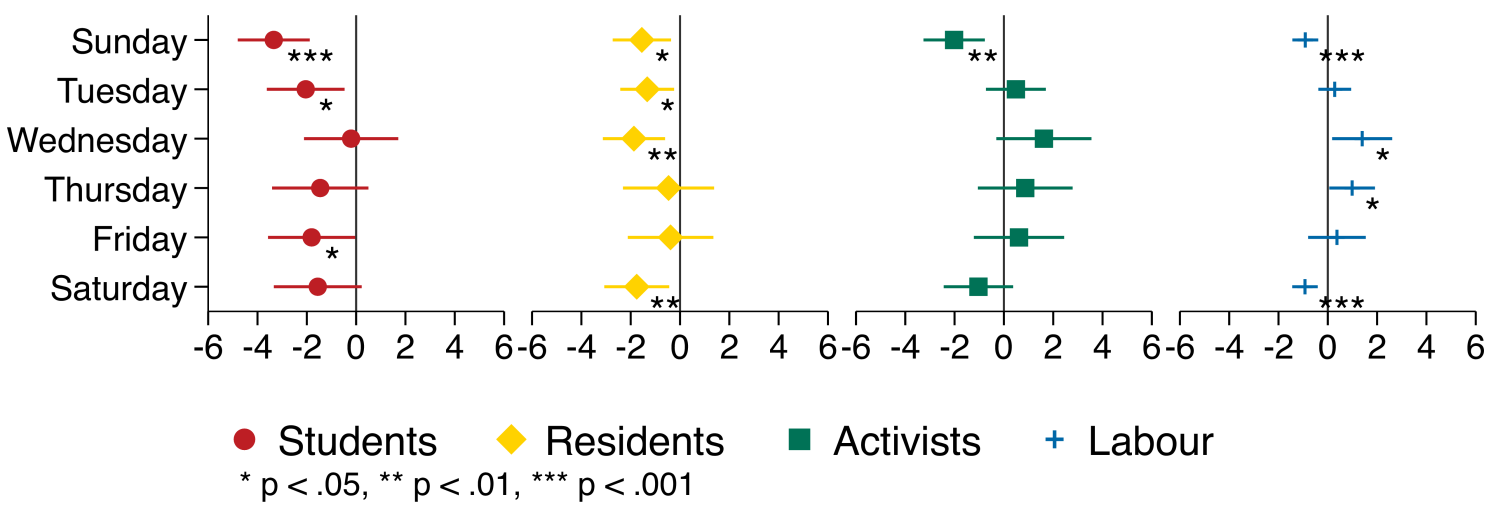

Figure 7: Protest participation by sector in Egypt and Tunisia

economic cost on Fridays when compared to the reference category. The signs for participation in static and disruptive forms of protest on Fridays are both positive, but are not statistically significant at $\mathrm{p}<.05$. Again, as per Figure 8 , we find a markedly different trend in Tunisia. When compared to protest on Monday, large economic, transitory, and disruptive protests fell coeval to one another during days that fell on the working week, with participation in disruptive and economic protest falling on the weekend. As in Egypt, we see no discernible pattern for participation in static protests.

Figure 9 examines how Egypt's focal day of protest influenced where people protested. The mobilizing effect of Fridays in shaping the spaces of mobilization is again borne out. When compared to Sunday, Egyptians were significantly more likely to protest in larger numbers on Fridays outside of places of worship and in public spaces. By the same measure, Egyptians were much less likely to protest in workplaces and on campuses on Fridays. In Tunisia no single day predicts greater 
(a) Egypt

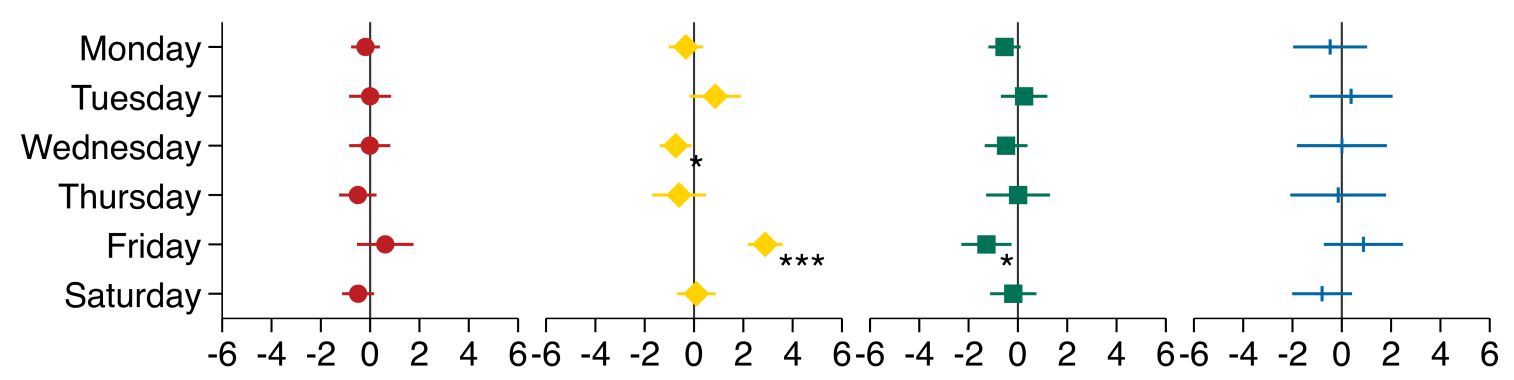
Disruptive $\quad$ Transitory $\square$ Economic + Static
${ }^{*} p<.05,{ }^{\star *} p<.01,{ }^{* \star *} p<.001$

(b) Tunisia

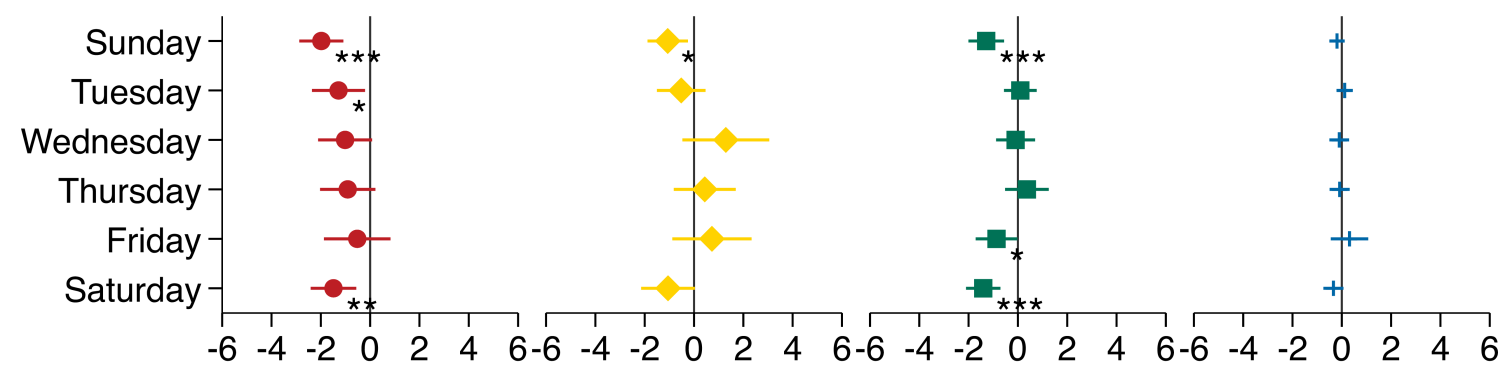

- Disruptive Transitory Economic + Static ${ }^{\star} p<.05,{ }^{\star \star} p<.01,{ }^{\star \star \star} p<.001$

Figure 8: Protest participation by repertoire in Egypt and Tunisia (a) Egypt

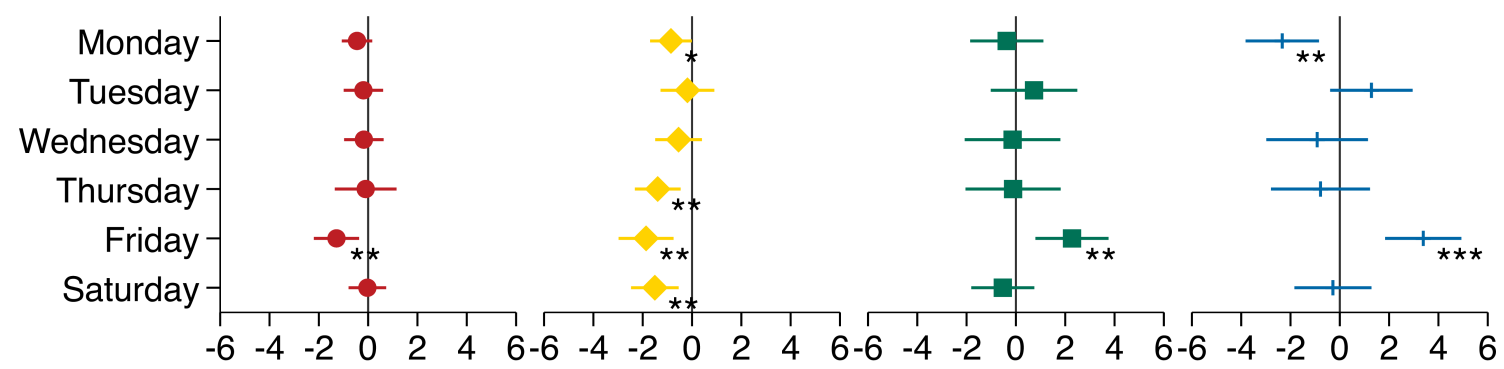

- Workplaces ${ }^{*} \mathrm{Campuses}$ - Public space + Worship
${ }^{* *} \mathrm{p}<.01,{ }^{* \star *} \mathrm{p}<.001$

(b) Tunisia

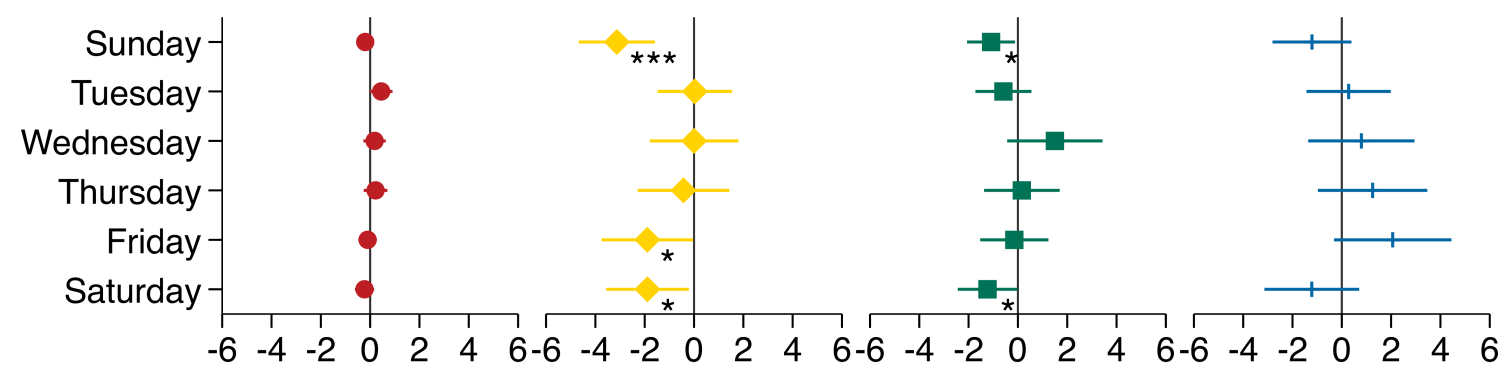

- Workplaces Campuses - Public space + Trade union ${ }^{*} \mathrm{p}<.05,{ }^{\star *} \mathrm{p}<.01,{ }^{\star \star *} \mathrm{p}<.001$

Figure 9: Protest participation by location in Egypt and Tunisia 
participation in where people protest, while campus protest is less likely at the end of the week and weekend (see Figure 9$).{ }^{7}$ Note that there is no direct comparison to places of worship: in Tunisia, ritual confluence at places of worship did not function as launching points for protest. Instead, UGTT offices often provided the locale for protest initiation and it is protest staged outside trade union offices that we test in place of mosques. As one Tunisian activist reflected in the post-Ben Ali period, "In Tunisia, the mosques of the revolution are the offices of the UGTT" (cited in Yousfi 2015: p.62). This is confirmed by event data. Over the year of the revolution and its aftermath, the event catalogue for Tunisia contains records for protest setting off from UGTT offices on 201 separate occasions. This represents the most frequently recurring start location for mobile protest. Among these, no single day predominates, and Fridays were the occasion for such protests just $14 \%$ of the time. By contrast, over the same period in Egypt, 268 protests set off from mosques, and of these $75 \%$ took place on Fridays. Thus, to the extent that commonplace locales for protest were in evidence in both Tunisia and Egypt, it was only in the latter that the spaces of contention exhibited a ritualized temporal rhythm, and this appears to be a consequence of political disorganization.

\subsection{Discussion}

Our findings are provocative. Theories of protest cycles and resource mobilization theory assume that social movements have a strong hand in setting the timing, locations and repertoires of contention. However, as the Egyptian case suggests,

${ }^{7}$ It is worth noting that, in the Egyptian case, certain days other than Fridays do exhibit, on occasion, significant differences in the locales and and sectors of protest. Mondays appear to be less likely occasions for protest at places of worship and Thursdays and Saturdays saw less campus-based and student protest, for example. Calendars may thus impact on protest in ways unconnected to focal Fridays. However, consistent with our central argument, Fridays are the only day on which there is a significant upsurge or decline in participation across multiple sectors, locales, and repertoires. 
in contexts of political disorganization, focal days of protest can strongly influence the "who," the "how," and the "where" of contentious collective action. Before discussing our results further, we should acknowledge their limitations. By focusing on the role of Fridays in patterning protest participation, our analysis is silent on the eventful dynamics of contentious politics. As a wealth of empirical research suggests, the decision to participate in protest can often be spontaneous or come in response to a particular event or incident (see e.g. Kurzman 2004; Snow and Moss 2014; Steinert-Threlkeld 2017a; Steinert-Threlkeld 2017b). While these more contingent, eventful logics were doubtless central to the initial outbreak of the revolutionary mobilization wave that struck Egypt in 2011, the patterning of contention otherwise exhibited obvious patterning in time, with large numbers of protestors waiting until Friday to air their grievances. Another concern pertains to the sectoral identity of protestors. It is undoubtedly the case that some protestors belonged to multiple sectors. Individual workers could mobilize at workplaces on weekdays and join their compatriots at a protest march on a Friday. However, of consequence for our analysis is the sectoral identity of protest organizers. Absent organizational underpinnings shared across multiple sectors, protest in Egypt exhibited striking regularity in the sectors that organized large-scale weekly protest and, as a result, the tactics and locales available for these protests.

Our contribution demonstrates the lessons that can be learned from an attention to the organizational foundations and consequent temporalities of protest. A growing literature is turning its attention to contentious politics for the explanation of both democratic breakthroughs and democratic consolidation (Chenoweth and Stephan 2011; Haggard and Kaufman 2016; Kadivar 2018). This scholarship investigates the effects of protest on democratic outcomes in a cross-national context, aggregating the attributes of mobilization episodes into single campaigns. By contrast, the foregoing analysis demonstrates what a finer-grained attention to the internal attributes of collective action can tell us about the potential of popular contention in transitional settings. In Egypt, the focal properties of Fridays, which 
functioned to segment and constrain popular mobilization, had several heretofore unappreciated consequences for the possibilities of mass mobilization. We review these below, pointing to three prinicipal strategic shortcomings of a reliance on ritualized action when contesting state power, which, we argue, functions to: 1) hinder system-wide action; 2) curtail disruptive protest; and 3) hamper coalition formation.

Firstly, having a focal day of protest that fell on a weekend ensured that activists (qua activists) and workers (qua workers) in Egypt rarely organized protest on the same day. ${ }^{8}$ In consequence, the post-Mubarak military government never faced truly system-wide mobilization — spanning public spaces, workplaces, and campuses — as activists demobilized during the working week. A reliance on focal days also meant labour protest during the post-Mubarak transition remained localized: workers rarely continued their protests into the weekend, when their workplaces were mainly closed. That economic protest was less likely on Fridays does not imply that mass protest in Egypt did not inflict any cost. Indeed, macro-economic costs of instability following the Arab Spring were sizeable (UNESCWA 2016). Of most note here is that mass protest rarely inflicted a direct cost on employers and authorities, while at the same time, labor protests rarely occurred in conjunction with other forms of protest as part of a larger campaign with a named political motivation. By contrast, such protest was seen frequently in Tunisia (see Yousfi 2015, ch.3). Counterfactually, it also seems reasonable to assume that, had workers' organizations and activist groups been mobilizing coeval to one another, then they would have been more likely to broker a shared front. As it was, labour mobilization unfolded at a distance from the big set piece Friday protests, contributing to the parochialization of this activism (see Barrie and Ketchley 2018).

Secondly, the focal qualities of Fridays ensured that successive regimes in Egypt rarely had to police multiple spaces of contention simultaneously. This has continu-

\footnotetext{
${ }^{8}$ As Friday prayer is typically reserved for males we use survey data to test, in the Appendix, for differences in the gender profile of protesters between Egypt and Tunisia. No significant differences are found.
} 
ing implications for the possibilities of mass protest in Egypt. With most workplaces and university campuses empty on weekends, the military and the Interior Ministry can concentrate their forces in just a few spaces, as activists look to make up for their organizational weakness by exploiting the focal qualities of Fridays. While this aided activists in coordinating collective action during the post-Mubarak transition when the security apparatus was weak and less willing to repress such highly visible protest, its long term effect has been to ease what Francsico (2010: 65-6) refers to as the "state's dilemma." When faced with multiple sites of protest, state security forces must confront the "traveling salesman problem" (Kauffman 1995, cited in Francisco 2010: 66); that is, the number of possible routes to take when policing protest, which increases exponentially as the number of protest sites increase. The now established tradition of amassing large numbers of people outside of mosques and moving to squares on Fridays has meant that the patterns of contentious action in Egypt are regular, predictable, and comparatively easy to police. ${ }^{9}$

This dynamic is well evidenced in Egypt following the military coup that removed Islamist president Muhammad Mursi in July 2013. In the subsequent period, the Muslim Brotherhood and their allies launched rolling street protests in a failed attempt to restore Mursi to office. Crucially, the Brotherhood, faced with mass arrests and the closure of their organizational infrastructure, fell back on the repertoire of amassing large numbers of protestors on successive Fridays. As Ketchley (2013: 15) chronicles, these large Friday protests were especially vulnerable to repression, as a reconstituted security apparatus concentrated their forces outside of mosques and on arterial routes. At the same time, the authorities installed large security bar-

\footnotetext{
${ }^{9}$ We should also reflect on the implications of mass Friday protest on the likelihood of defection. Scholars have theorized that, when faced with mass protest drawn from diverse constituencies, security forces may be more likely to defect (Barany 2016). However, Friday protests in Egypt, as we describe above, were rarely cross-sectoral. Further, after Mubarak's ouster, successive regimes have made every effort to secure against defection by employing thugs, military police, and running columns when interacting with protestors (Ketchley 2017, ch. 3).
} 
riers on roads leading to focal spaces for protest, which were preemptively closed on Friday mornings. The Ministry of Religious Endowments also closed mosques associated with Muslim Brotherhood protests, and imposed a pre-approved Friday sermon that had to be delivered by a graduate of al-Azhar. Denied these spaces to mobilize, the Brotherhood struggled to adapt and ultimately demobilized (see Ketchley 2017, ch.6).

Finally, our results demonstrate that protestors mobilizing on Fridays were much more likely to participate in transitory forms of protests. As several studies have noted, new protest organizations are more likely to crystallize in static occupations, protest encampments, and on barricades, when the opportunities to co-mingle and strategize is greatest (Dzenovska and Arenas 2012; Traugott 2010). That the primary mode of contestation engaged in by protestors lasted just a few hours (at most) surely inhibited these processes. Even the spectacular mass protests staged in Tahrir Square were often short-lived; over the transitional period, protest numbered in the hundreds of thousands on consecutive days in Tahrir on only one occasion (21-22 November), and consecutively in the tens of thousands on two occasions (19-20 and 23-24 November). Over the course of 2011, 44 percent of Tahrir protest occurred on a Friday. Against this backdrop, it is telling that no new national movements emerged in Egypt during the critical first year of the post-Mubarak transition.

\section{$7 \quad$ Focal days in the MENA}

Thus far, our analysis has focused on two countries undergoing democratic transitions in the aftermath of revolutionary uprisings. This raises questions of external validity and the generalizability of our findings. Following Biggs (2018), our main analyses make use of protest participation in order to more properly capture collective action. The aggregate temporal patterns we identify are still discernible when using event counts as the outcome, however. ${ }^{10}$ The Armed Conflict Location and Event Dataset (ACLED) includes cross-national event data for each of the countries

\footnotetext{
${ }^{10}$ We use event counts as few secondary datasets record the number of participants.
} 
that saw significant protest activity during the Arab Spring (Raleigh et al. 2010). ${ }^{11}$ Using these data, we analyse country-day event counts for five further countries in the MENA, as well as Egypt and Tunisia over the period January 2011-January 2019.

As above, bar graphs display raw counts aggregated to the day of the week, while the coefficient plots display results from a negative binomial regression of daily event counts with day of the week tested as a categorical variable (again, populating missing dates with zero counts to avoid upwardly biased means). The results are displayed in Figure 10. A striking pattern emerges: in every one of the countries that saw sizeable mobilization in 2011, we have evidence of a focal day of protest - with the exception of Tunisia. In all of the countries with a Sun-Thu working week including Egypt, this focal day falls on a Friday. In Morocco, the only other MENA country with a Mon-Fri working week, the focal day is Sunday. In Tunisia, by contrast, we see diminished protest on weekends but sizeable protest during the working week.

A number of comments are worthwhile here. First, confirmation with event data of the temporal patterns in Egypt and Tunisia identified using protest participation data boosts confidence in the out-of-sample validity of our estimates. Second, the results provide a counter to the claim that focal days were unavailable to Tunisians due to the particularities of their working week. In Morocco, where a Mon-Fri working week is in operation, the focal day falls on Sunday. Note also that Morocco, like Tunisia, is 99 percent Sunni Muslim. According to Arab Barometer Wave III, 72 percent of male Moroccans reported going to Friday prayers "always" or "most of the time." Still, despite the obvious availability of Friday as a focal point solution, it did not function as such. Instead, the February 20 Movement (Feb20), the movement that spurred Morocco's Arab Spring protests, was so named after the Sunday on which February 20 of 2011 fell. ${ }^{12}$ Third, there is good reason to think that these cases

\footnotetext{
${ }^{11}$ The exception is Yemen, for which reliable daily event data from the period 2011 onwards is not available.

${ }^{12}$ Sundays would continue to serve a date-setting function for Morocco's burgeoning, but ultimately
} 

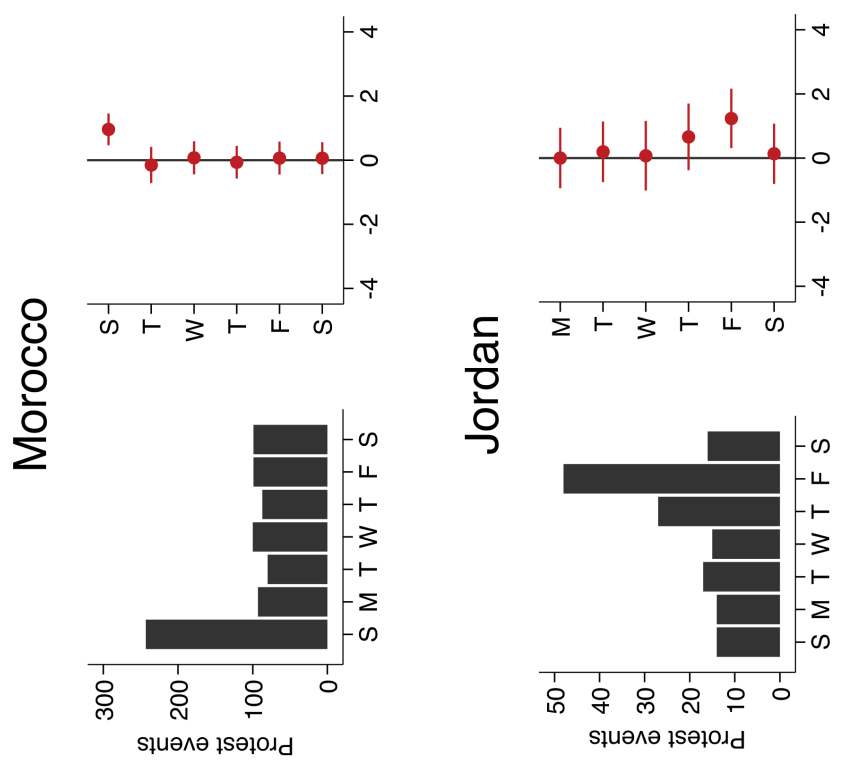

告
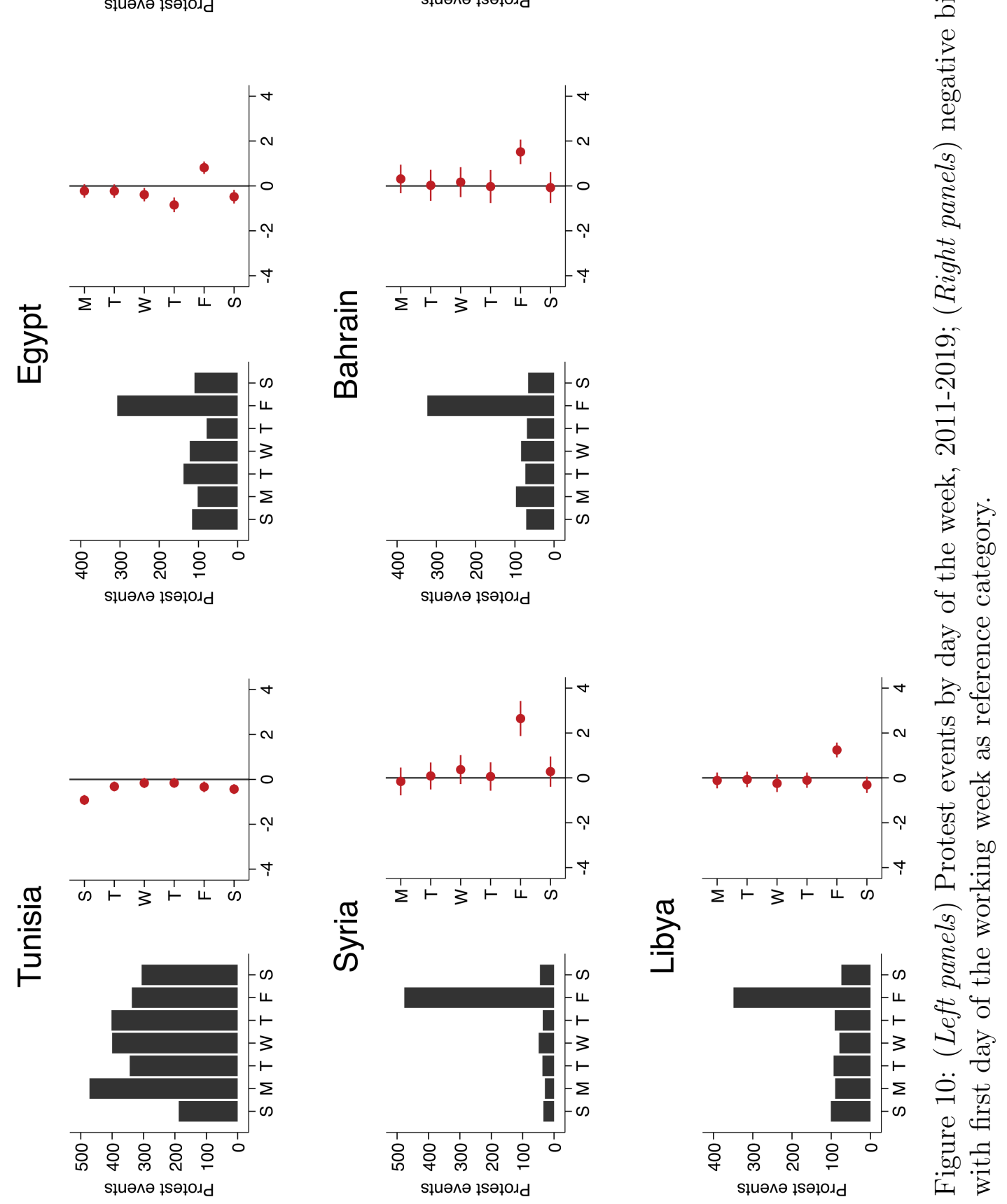
may not be independent of one another. In Syria, for example, activists explicitly took inspiration from events in Egypt to call for named Friday protests against the Assad regime - even using the same naming conventions, e.g. the "Friday of Anger" (Droz-Vincent 2014: p.44). Here, it appears that, having been successfully trialled in Egypt, other hastily assembled protest coalitions adopted Friday as a focal day to overcome their organizational weakness and coordinate mass protest.

While sufficient information is not available to analyse the effect focal days had on the sectors, locations, and repertoires of protest in these countries, it follows that we could plausibly expect to find a pattern not dissimilar to that which obtained in Egypt. Organizational weakness, in other words, and the consequent constrained potential of protest, likely characterizes numerous other countries in the MENA where protestors rely on a focal day to coordinate mobilization.

\section{Conclusions}

Focal days of protest have emerged as important tools for massing large numbers of citizens during episodes of revolutionary mobilization and mass uprising, but their impact on patterning longer cycles of protest has not previously been established. In this article we have compared the dynamics of mass mobilization in Egypt and Tunisia during the 2011 Arab Spring and its aftermath. We have argued that a reliance on focal points is in large part a function of political disorganization, and that focal days of mobilization can segment and constrain contentious collective action following a revolutionary episode. In the Egyptian case, focal days definitively patterned protest, but in a way that had deleterious consequences for the prospects of street-level demands. The temporal and strategic repertoires exhibited during the transitional period proved unable to diversify, form broader coalitions, or inflict

fragile, protest coalition in ensuing years. This reliance on a focal day of protest, however, led to a growing sense of apathy. As one former member of Feb20 would put it: "Going on protesting in the streets every Sunday with repetitive slogans is pointless and leads nowhere" (cited in Benchemsi 2014: 229). 
system-wide disruption. In this, we provide insight into an oft-overlooked dimension of contentious politics and democratization: how inherited repertoires of contention, and here focal days of mass protest, may function to limit the democratic potential of mobilization from the street, particularly in conditions of organizational weakness.

We cast Egypt into comparative relief against Tunisia where there was no single focal day of protest due, in large part, to the role of organized labour in coordinating protest. In this, Tunisia adheres to the expectations of the literatures on resource mobilization and protest cycles. One objection to this argument would be that organized movements might still stand to benefit from the use of focal days. Put otherwise, given their seeming success in Egypt (and adoption across numerous other countries in the MENA following the 25 January Revolution) why did the UGTT in Tunisia not also exploit their mobilizational potential? In response, we would say that the dilemma of coordinating mass protest is only really salient in contexts of organizational weakness. Where activists cannot be sure of support, ritual activity on a focal day provides a coordination solution. Well-resourced movement simply do not face this dilemma and thus the decision-making calculus operates outside of these considerations. Furthermore, focal days involve two key costs that movements would wish to avoid. First, it would mean relinquishing control over the mobilization process to a set of rituals outside of the immediate reach of the movement itself. Second, by not responding immediately to unfolding events in the political process, movements would cede a strategic advantage to forces threatening a transition.

Our supplementary analysis of protest event counts in five further countries of the MENA points to a widespread reliance on focal days. Again, it is revealing that the only country not to have a focal day - Tunisia - is also arguably the only country to boast well-resourced, national movement organizations with the willingness to launch protest. Unfortunately, reliable daily interval event data for other countries undergoing revolutionary upheavals is rare - but it seems intuitive that having a focal day of protest that falls on a weekend will have particular consequence for the MENA region, or else Muslim-majority countries in South and Southeast Asia 
(see Butt 2016). The Egyptian experience provides additional translatable lessons. Here, our findings hold out important implications for the study of contemporary revolutions, and in particular the fate of rapidly convened revolutionary coalitions. Despite the repeated amassing of huge numbers of protesters in loose coalitions of challengers - the repertoire common to new "urban civic revolutions" (Beissinger 2013) that increasingly subside into democratic transitions - contentious collective action may yet fail to achieve lasting gains. In this, we contribute to an emerging body of work seeking to unite contentious politics and democratization literatures. The rapid mobilization of a diverse "negative coalition" of revolutionary contenders, while able to unseat dictators, bears heavily the birth scars of its origins in the brief revolutionary conjuncture, and this can profoundly influence the shape and outcomes of protest cycles in the revolutionary aftermath. 


\section{References}

Abdelrahman, Maha. 2013. "In Praise of Organization: Egypt between Activism and Revolution." Development and Change 44(3):569-585.

Atkinson, AC. 1981. "Two graphical displays for outlying and influential observations in regression ." Biometrika 68(1):13-20.

Barany, Zoltan. 2016. How Armies Respond to Revolutions and Why. Princeton: Princeton University Press.

Barrie, Christopher, and Neil Ketchley. 2018. "Opportunity without Organization: Labour Mobilization in Egypt after the 25th January Revolution." Mobilization 23(2): 181-202

Beissinger, Mark R. 2013. "The Semblance of Democratic Revolution: Coalitions in Ukraine's Orange Revolution." American Political Science Review 107(3):574592.

Benchemsi, Ahmed. 2014. "Morocco's Makhzen and the Haphazard Activists" in Lina Khatib and Ellen Lust eds. Taking to the Streets: The Transformation of Arab Activism. Baltimore: Johns Hopkins University Press.

Biggs, Michael. 2018. "Size Matters: Quantifying Protest by Counting Participants." Sociological Methods \& Research 47(3):351-383.

Butt, Ahsan I. 2016. "Street Power: Friday Prayers, Islamist Protests, and Islamization in Pakistan." Politics and Religion 9(1): 1-28.

Chenoweth, Erica, and Maria J. Stephan. 2011. Why Civil Resistance Works: The Strategic Logic of Nonviolent Conflict. New York: Columbia University Press.

Chwe, Michael Suk-Young. 2001. Rational Ritual: Culture, Coordination, and Common Knowledge. Princeton: Princeton University Press.

Clarke, Killian. 2014. "Unexpected Brokers of Mobilization: Contingency and Networks in the 2011 Egyptian Uprising" Comparative Politics 46(4):379-397.

Clemens, Elisabeth S. 1993. "Organizational Repertoires and Institutional Change: Women's Groups and the Transformation of U.S. Politics, 1890-1920." American Journal of Sociology 98(4):755-798. 
Clemens, Elisabeth S. and Debra C. Minkoff. 2004. "Beyond the Iron Law: Rethinking the Place of Organizations in Social Movement Research" in David A. Snow, Sarah A. Soule and Hanspeter Kriesi eds. The Blackwell Companion to Social Movements. Oxford: Blackwell.

Dalton, Russell, Alix Van Sickle, and Steven Weldon. 2010. "The IndividualInstitutional Nexus of Protest Behaviour." British Journal of Political Science 40(1):51-73.

Droz-Vincent, Philippe. 2014. "State of Barbary' (Take Two): From the Arab Spring to the Return of Violence in Syria," Middle East Journal, 68(1): pp. $33-58$

Dzenovska, Dace, and Iván Arenas. 2012. "Don’t Fence Me In: Barricade Sociality and Political Struggles in Mexico and Latvia." Comparative Studies in Society and History 54(3):644-678.

United Nations Economic and Social Commission for Western Asia. 2016. "Survey of Economic and Social Developments in the Arab Region 2015-2016." United Nations Publication. Available at: https://www. unescwa.org/publications/ survey-economic-social-development-arab-region-2015-2016. Last accessed 06 Sep. 2019.

Fisher, Dana R., Kevin Stanley, David Berman, and Gina Neff. 2005. "How do Organizations Matter? Mobilization and Support for Participants at Five Globalization Protests." Social Problems 52(1):102-121.

Francisco, Ronald A. 2004. "After the Massacre: Mobilization in the Wake of Harsh Repression." Mobilization 9(2):107-126.

Francisco, Ronald A. 2010. Collective Action Theory and Empirical Evidence. New York: Springer.

Gerhards, Jürgen and Dieter Rucht. 1992. "Organizing and Framing in Two Protest Campaigns in West Germany." American Journal of Sociology 98(3):555-596.

Gunning, Jeroen, and Ilan Zvi Baron. 2013. Why Occupy a Square? People, Protests and Movements in the Egyptian Revolution. London: Hurst \& Company. 
Haggard, Stephan and Robert R. Kaufman. 2016. Dictators and Democrats: Masses Elites, and Regime Change. Princeton: Princeton University Press.

Hilbe, Joseph M. 2011. Modeling Count Data. Cambridge: Cambridge University Press.

Hmed, Choukri. 2015. "Abeyance Networks, Contingency and Structures: History and Origins of the Tunisian Revolution." Revue Française de Science Politique $62: 31-53$.

Jadaliyya. 2019. "A Hirak Glossary: Terms from Algeria and Morocco," 13 Jun. Available at: https://www.jadaliyya.com/Details/38734. Last accessed 05 Sep. 2019.

Kadivar, Ali. 2018. "Mass Mobilization and the Durability of New Democracies." American Sociological Review 83(2): 390-417

Kauffman, Stuart. 1995. At Home in the Universe: The Search for the Laws of Self-Organization and Complexity. Oxford: Oxford University Press.

Ketchley, Neil. 2013. "The Muslim Brothers Take to the Streets," Middle East Report, Issue.269: 12-17.

Ketchley, Neil. 2017. Egypt in a Time of Revolution: Contentious Politics and the Arab Spring. Cambridge: Cambridge University Press.

Koopmans, Ruud and Susan Olzak. 2004. "Discursive Opportunities and the Evolution of Right-Wing Violence in Germany." American Journal of Sociology 110(1):198-230.

Kurzman, Charles. 2004. The Unthinkable Revolution in Iran. Cambridge: Harvard University Press.

Lichbach, Mark Irving. 1995. The Rebel's Dilemma. Ann Arbor: University of Michigan Press.

Lohmann, Susanne. 1994. "The Dynamics of Informational Cascades: The Monday Demonstrations in Leipzig, East Germany, 1989-91." World Politics 47(1):42101.

Masoud, Tarek. 2014. 2014. Counting Islam: Religion, Class and Elections in 
Egypt. Cambridge: Cambridge University Press.

McAdam, Doug and Hilary Schaffer Boudet. 2012. Putting Social Movements in Their Place: Explaining Opposition to Energy Projects in the United States, 2000-2005. Cambridge: Cambridge University Press.

McCammon, Holly J. 2012. Women's Jury Movements and Strategic Adaptation: A More Just Verdict. Cambridge: Cambridge University Press.

McCarthy, John D., and Mayer N. Zald. 1977. "Resource Mobilization and Social Movements: A Partial Theory." American Journal of Sociology 82(6):1212-1241. Minkoff, Debra C. 1997. "The Sequencing of Social Movements." American Sociological Review 62(5):779-799.

Moral, Rafael A., John Hinde, and Clarice G B Demétrio. 2017. "Half-Normal Plots and Overdispersed Models in R: The hnp Package." Journal of Statistical Software 81(10):1-23.

Oliver, Pamela E. and Gregory M. Maney. 2000. "Political Processes and Local Newspaper Coverage of Protest Events: From Selection Bias to Triadic Interactions." American Journal of Sociology 106(2):463-505.

Opp, Karl-Dieter and Christiane Gern. 1993. "Dissident Groups, Personal Networks, and Spontaneous Cooperation: The East German Revolution of 1989." American Sociological Review 58(5):659-680.

Pfaff, Steven and Guobin Yang. 2001. "Double-Edged Rituals and the Symbolic Resources of Collective Action: Political Commemorations and the Mobilization of Protest in 1989." Theory and Society 30(4):539-589.

Raleigh, Clionadh, Andrew Linke, Havard Hegre, and Joakim Karlsen. 2010. "Introducing ACLED: An Armed Conflict Location and Event Dataset: Special Data Feature." Journal of Peace Research 47(5):651-660.

Rasler, Karen. 1996. "Concessions, Repression, and Political Protest in the Iranian Revolution." American Sociological Review 61(1):132-152.

Schelling, Thomas. 1960. The Strategy of Conflict. Cambridge: Harvard University Press. 
Schock, Kurt. 2005. Unarmed Insurrections: People Power Movements in Nondemocracies. Minneapolis: University of Minnesota Press.

Snow, David A., and Dana M. Moss. 2014. "Protest on the Fly: Toward a Theory of Spontaneity in the Dynamics of Protest and Social Movements." American Sociological Review, 79(6):1122-1143.

Steinert-Threlkeld, Zachary C. 2017a. "Spontaneous Collective Action: Peripheral Mobilization During the Arab Spring," American Political Science Review 111(2):379-403.

Steinert-Threlkeld, Zachary C. 2017b. "Longitudinal Network Analysis with Incomplete Data," Political Analysis 25(3):308-328.

Tarrow, Sidney. 2011. Power in Movement: Social Movements and Contentious Politics. Cambridge: Cambridge University Press.

Taylor, Verta. 1989. "Social Movement Continuity: The Women's Movement in Abeyance." American Sociological Review 54(5):761-775.

Traugott, Mark. 2010. The Insurgent Barricade. Berkeley: University of California Press.

Tucker, Joshua A. 2007. "Enough! Electoral Fraud, Collective Action Problems, and Post-Communist Colored Revolutions." Perspectives on Politics 5(3):535-551.

Zald, Mayer N. and John D. McCarthy. 2002. "The Resource Mobilization Research Program: Progress, Challenge, and Transformation." in Joseph Berger and Morris Zelditch eds. New Directions in Contemporary Sociological Theory. Oxford: Rowman and Littlefield. 


\section{A Appendix}

\section{A.1 Methodological appendix - Event data sources Tunisia}

While the majority of protest event analyses derive their data from newspaper reports, this was not possible during for the twenty-nine day revolutionary uprising in Tunisia where a media blackout aimed specifically at stymieing the flow of information. We were able to overcome this obstacle by triangulating multiple alternative sources of information. We made use first of Facebook pages, two of which were already in operation before the uprising, and two of which were created for the specific purpose of posting news of protests. The names and details of these pages are below. The pages were archived in PDF format, retaining the link structure, thereby enabling us manually to code protest events from each of them. These sources were then supplemented with multiple further sources of information, including some national newspapers, international newspapers, and a post-revolutionary investigatory commission. The groups used, as well as further sources used for constructing the event catalogue for the revolutionary period, are listed below. In a subsequent section, we detail the sources used for the post-revolutionary period. Events were coded entirely by XXX.

\section{Tunisia event data sources for revolutionary period $(17 / 12 / 2010-14 / 01 / 2011)$}

\section{Facebook}

• Chaab Tunis Yahriq fi Ruhu ya Siyyadat alRa'is (Mr. President, the People of Tunisia are On Fire (PTON)). This page was set up upon the outbreak of protests, as the title of the group suggests. It went through six iterations as it was continually hijacked by unknown cyber attackers, likely linked to the Ben Ali regime. ${ }^{13}$ When hijacked, the founders would set up a new page by the same title but with the number of the version of the group appended. The pages contained information on protest for everyday of the uprising with the exception of the period 02/01/11-08/01/11 when the page was down. Protest reports would often report on the type of protest (e.g., march, occupation, demonstration), include some mention of size (e.g. 'a group of', 'large', 'huge'), and give some mention of source (most often 'union sources'). When the report cited 'unconfirmed reports', the report was not included in the event catalogue. In total these pages provided information on 193 protest events, 125 of which were corroborated with a secondary source (video, national or international news media, Bouderbala Commission). Out of the 193 protest events recorded from this source, 78 could be checked against video evidence. Figure A.1 gives an example of a video protest report posted to this page.

- Wikalat Anba' Taharrukat al-Shari'a al-Tunisi (News Ägency of the Tunisian Street (NATS)). This page was also set up upon the outbreak of protests in Sidi Bouzid and protest reports followed a similar formula to the above page. It has two iterations, after the first was also hijacked. The pages contained information on protest for the period 02/01/11-14/01/11. In total, this page provided information on 195 protest events, of which 111 could be matched with a secondary source. Out of the 195 protest events recorded from this source, 49 could be checked against video evidence. Figure A.2 gives an example of a typical protest report from this page.

\footnotetext{
${ }^{13}$ An interview with the founders of the page can be accessed here: http://www. thedailybeast. com/articles/2011/01/15/tunisa-protests-the-facebook-revolution.html, last ac-
} 


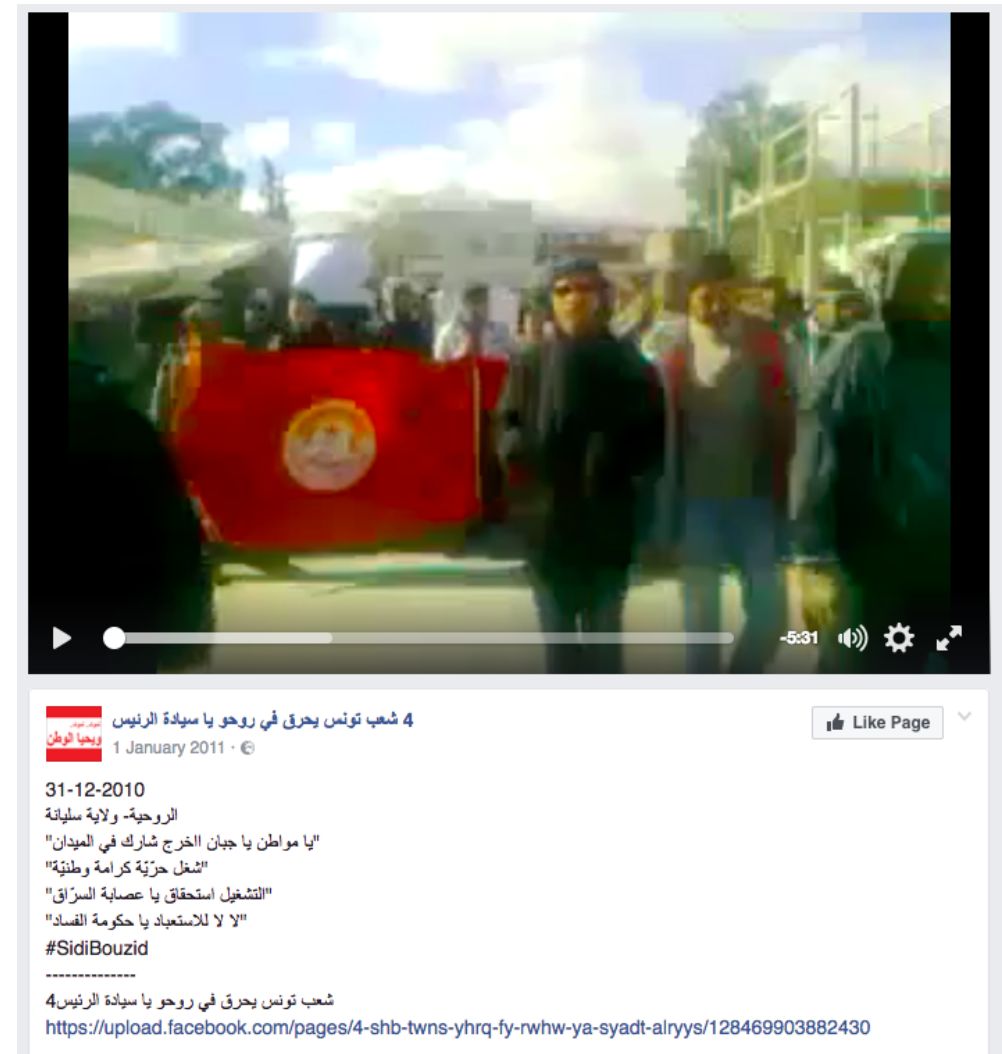

Figure A.1: Typical video protest report from PTON. Text underneath reads: 31/12/10: Er-Rouhia-Siliana Governorate. Subsequent lines detail chants heard during the protest, including: "Don't be a coward, go out onto the street!"; "Work, freedom, national dignity!"; "Work is a right, you gang of thieves!", "No to tyranny and corrupt government!".

- ما عندي مانقلك 'Ayndi Mankolek (I Have Nothing to Say to You). This page was already in existence prior to the revolution. It was a forum for dissident opinion and took positions against, for example, online censorship. This page was active for the entire period of the uprising. In total, this page provided information on 33 protest events, 27 of which could be matched with a secondary source, and 10 of which could be checked against video evidence.

- $\boldsymbol{T A K R I Z}$ (Ball-Breaker). This page was already in existence prior to the revolution and ran alongside the now-defunct website takriz.com, founded in 1998. It was a forum for dissident opinion, anti-censorship activism, and often irreverent commentary on Tunisian affairs. Upon the outbreak of the revolution, its administrators began posting videos and reports of protests, encouraging their members to go out and protest at the same time. Unfortunately, the page was not available for the period 02/1/11-14/01/11. In total, this provided information on 41 protest events, of which 33 could be verified against a secondary source.

\section{Radio/National News}

- راديو كلمة تونس Radio Kalima Tunis (Word of Tunisia Radio). Kalima Tunis is a radio station set up in 2008 by journalist and human rights campaigner Sihem Bensedrine,

cessed: 19/03/2018. 


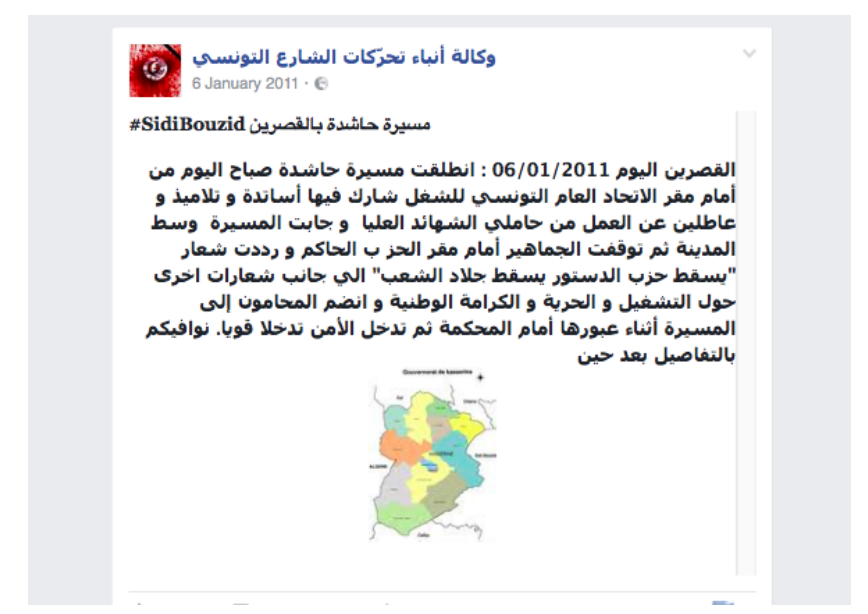

Figure A.2: Typical protest report from NATS. Text reads: "Kasserine, today 06/01/2011: A large march of students, teachers, unemployed and unemployed graduates left this morning from the UGTT offices, circling the city before stopping outside the RCD office at which point the chant "Down with the Dostour Party, down with the executioner of people" was heard alongside other chants calling for work, freedom, and national dignity. Lawyers also joined in the protest as the march went past the court building, at which point the police forcefully intervened. We will keep you updated".

and Omar Mestiri. The radio station operated from France after being banned in 2009, but still had journalists on the ground. It published multiple dispatches daily on the unfolding of protest events that have been archived by online news aggregator turess . com. In total, Kalima Tunis provided information on 342 protest events, of which 81 could corroborated with a secondary source.

- الشروق Al Chourouk (Sunrise). Pro-regime newspaper that only began to report on protest in the closing stages of the uprising. Nonetheless, it provided information on 86 protest events, of which 85 could be checked against a secondary source. Copies of these reports were obtained from turess.com. These articles were also checked against archived paper copies of the newspaper in the Centre de Documentation Nationale archive in Tunisia in order to check for any omissions on the turess . com website. No significant omissions were found.

\section{International News}

- International news sources were also used when available. Two of these took the form of evening news reports, archived versions of which were posted on the Facebook pages described above. The first of these is Al Jazeera: The Maghreb Harvest (الجزيرة: الحصاد المغربي). This was a daily news round up of events in Arab North Africa that, given the ongoing protests in Tunisia, focused primarily on Tunisian affairs over the twenty-nine days of the uprising. France 24 (فرانس 24) also provided a daily round of news in North Africa, with a particular focus on Tunisia over the twenty-nine days of the revolt. News articles from Arabic-, French-, and English-language news outlets were also archived when posted on the Facebook groups listed above. These included: BBC News, Agence France Presse, Le Point, Le Monde, Reuters Arabic, Agence Tunis Afrique Presse, Business News Tunisia. Further articles from international news media 
were extracted from Google News. These were then all matched against existing protest reports. In total, these sources together provided information information on 50 separate protest events.

\section{Other sources}

- Two weekly newspapers of the few oppositional parties nominally authorized in Tunisia, Attariq Al Jadid (of the centre-left Ettajdid party), and Al Mawkif (of the leftist Parti démocrate progressiste), as well as one, Echaab (of the national trade union federation the UGTT), were sought out from the Centre de Documentation Nationale and the UGTT's own archives to provide further information with which to cross-check the Facebook protest reports, however these provided only limited information on protest occurrence.

\section{Videos and Photos}

- Videos. Videos were often posted to the Facebook groups listed above accompanied with reports on the protest itself. In total 106 videos were found, all of which were matched with a protest report. Videos were nearly all accompanied by a date in the comments under the video. Alternatively, videos would be accompanied by a comment such as "Situation today in [name of town/city]", meaning the date could then be assumed as the date of the posting itself.

- Photos. Photos were also often posted to the Facebook groups listed above accompanied with reports on the protest itself. In total 25 photos were used and matched with protest reports. Photos would also either be accompanied by a date or the date of the event could be deduced from comments in the post e.g. "Photos from protest yesterday in [name of town/city]".

\section{Bouderbala Commission}

- The full name of the investigatory commission, now commonly referred to after its Head, Taoufik Bouderbala, is the "Commission nationale d'investigation sur les abus enregistrés au cours de la période allant du 17 décembre jusqu'à l'accomplissement de son objet". The full report is available online here: http://www.leaders.com.tn/ uploads/FCK_files/Rapport\%20Bouderbala.pdf In this first report, the Commission looked into abuses committed from 17 December 2010 up to the first elections on 23 October 2011. Bouderbala is himself a lawyer and Honourary President of the Tunisian Human Rights League (Ligue tunisienne des droits de l'homme). The report is itself the subject of some scrutiny as it is perceived not to have gone far enough in identifying individuals responsible for the deaths of protesters. Further, the list of deaths published was described as "provisional" and the Commission has yet to publish its final version. While the existing list may only be provisional, and it does not identify police responsible, the report is nonetheless comprehensive (running to over 1,000 pages) and provides a rich source of information for the purposes of this study. While reports of injuries contain sometimes sparse information, the Bouderbala Commission verified deaths with visits to the homes of the bereaved and checked reports against available medical records, thus providing a confident estimate of levels of repression witnessed during protests. The reports included the circumstances of the death, the date of the incident, and the institutional identity of the perpetrator. Only those that stated explicitly that the 
individual was killed at the hands of state security (police, national guard or army), or was killed during a protest, were included for the analysis. The report also contains information on the locations of protest, but limits its reports to the closing stages of the revolution. The information contained therein was nonetheless checked against the event data for purposes of further corroboration.

\section{Tunisia event data sources for post-revolutionary period (15/01/2011-01/01/2012)}

For the period following the revolutionary uprising, we principally used al-Chourouk newspapera national daily that began reporting on protest towards the end of the uprising and continued to report on protest thereafter. Copies of articles from these newspapers were located on the online news aggregator and archiving tool turess.com. al-Chourouk is printed from TuesdaySunday. For Mondays, copies of news wires and articles from TAP and La Presse were coded in its place. For select periods, al-Chourouk articles were also not available. The periods for which al-Chourouk were not available are listed below, alongside the sources coded in its place:

- 28/04/2011-02/05/2011 missing for al-Chourouk. Coded La Presse and TAP in its place

- 22/07/2011-29/07/2011 missing for al-Chourouk. Coded La Presse and TAP in its place

- 29/08/2011-01/09/2011 missing for al-Chourouk. Coded La Presse and TAP in its place

- 04/11/2011-28/11/2011 missing for al-Chourouk. Coded La Presse and TAP in its place

- 21/12/2011-31/12/2011 sporadic for al-Chourouk.Coded La Presse and TAP in its place

For the tumultuous period of 15/01/2011-31/01/2011, we supplemented al-Chourouk with PTON and NATS, which continued to report on protest in the period immediately following Ben Ali's ouster, as well as Kalima Tunis and La Presse. A note on the use of al-Chorouk, La Presse, and TAP is worthwhile here. Tunisia's media structures were not independent at the time of the uprising, thus explaining their censorship of protest reporting during much of the initial uprising. Following the uprising, however, we see these newspapers begin reporting programatically and extensively on protest. Protest reports would follow a format similar to those seen in the Egypt sources outlined below, listing governorate-by-governorate the protests witnessed on that day. Also notable is the dramatic change in tone of reporting in al-Chorouk immediately following Ben Ali's fall, whereupon they began publishing highly critical reports of the repression meted out to protesters as well as the Ben Ali reign as a whole. The frontpage headline of al-Chorouk on the day of Ben Ali's fall read "The will of the people victorious" (إرادة الشعب تنتصر). See also https://www.20minutes.fr/monde/656500-20110120monde-un-vent-liberte-souffle-medias-tunisiens[fr.] for reporting with journalists from al-Chourouk and La Presse on the immediate lifting of reporting restrictions following Ben Ali's fall. Throughout the coding process, we also did not encounter a single article that articulated a negative judgment of protests. Instead, protest events were reported programatically and without comment.

For this paper, we conducted an additional check on participation counts by dropping or recoding events for which there was some uncertainty around appropriate coding decisions. For the Tunisia event catalogue, reporting often described protests as "large" or "huge" but did not give precise figures. When protests were described this way but precise figures were not given, a decision was made to scale the conventional counts (i.e., 301 for demonstration or march as described above) by a factor of ten. In the Tunisia dataset there were 48 protests described as "large" and 6 described as "huge". All protests described as "huge" could be 
triangulated against a photo or video. Of the protests described as "large", we were able to triangulate 27 with a video or photo and verify the accuracy of the participation codings. 12 we were unable to triangulate with a photo, video, or secondary source. The majority (7) of these took place during the month of January 2011. Removing these events or scaling them down by a factor of ten does not substantively change our results in any way. A further 8 events were described as "large" but involved only one sector (e.g., police). In these cases, normal codings were used (i.e., they were not scaled by ten). Again, inflating/deflating participation estimates accordingly or dropping these observations does not alter our results in any substantive sense. A final observation contained conflicting reports as to the size of the protests (hundreds versus thousands) and concerned a protest march in Sidi Bouzid on January 24, 2011. Removing or rescaling this events does not change our results.

\section{A.2 Methodological appendix - Event data sources Egypt}

Due to the relatively freer media infrastructure in Egypt at the time of the uprising in 2011, we are able to rely on newspapers alone for the construction of the entire Egypt dataset. al-Masry al-Youm, Egypt's largest independent newspaper, was the principal news source used.

The event data for Egypt was handcoded and derives from protest reports published in three Egyptian national newspapers: al-Masry al-Youm, al-Dostor, al-Shorouk. The catalogue extends from 1 January 2011 to 1 January 2012 and contains detailed information on 4,917 protest events. The principal newspaper used was al-Masry al-Youm. However, for certain periods, as with the Tunisia event catalogue above, during periods of intense protest, this newspaper was supplemented with two further newspapers-al-Dostor, al-Shorouk - to combat potential "news hole" effects whereby events would go underreported due to the limited column inches in newspapers. These periods included the 25th January revolution up to the ouster of Hosni Mubarak (25/01/2011-11/02/2011) and the Events of Muhammad Mahmoud Street (19/11/2011-24/11/2011). 


\section{A.3 Methodological appendix - Event catalogue codebook for Tunisia and Egypt}

The relevant variables used in this article, and their codings, for the Tunisia and Egypt event catalogues are listed below:

1. Date: The date of the protest occurring. This could be deduced from the report itself and the date attached to the post in Facebook, for example, or the date of the article posted on the website of a newspaper. In cases where protests were reported to have been ongoing for $x$ number of days, protest reports would be entered for day $t$ and the period $t$ - $x$. On the rare occasion that the article specifies a protest as ongoing for "more than a week" or "more than a month", this is coded as one day more than the time period specified.

2. Protest participation: Estimated participation in the protest. Here, we employed the coding convention used in the European Protest and Coercion Dataset (Francisco 2000). Protest size is often reported in factors of ten-e.g., "tens", "hundreds", "thousands". In such cases, these are coded as "31", "301", and "3001" respectively. Protests would occasionally also be described as "large" or "huge", in such cases, participation was increased by a factor of ten. When no further information was provided "demonstration/protest" (manifestation/protestation or مظاهرة/احتجاج) was coded as "301", as was march (marche or مسيرة) and strike (grève or عاضضراب), while a regional general strike (grève régionale or إضراب عام محلي) would be coded as 3001 if in just one delegation and 30,001 if in an entire governorate. Blockade (bloquer la route or قطع الطريق), human chain (only Egypt) سلسلة بشرية), and attack (attaque or مهاحمة) would be coded as 31. Occupations (occupation or اعتصام) would be coded as 301 when outside and 31 when occupying the inside e.g. of a building. Sit-ins (sit-in or وقفة احتجاجية) would be coded as 31. These participation count conventions were elaborated on the basis of what we observed to be the modal protest size for a given repertoire. In Egypt, Tahrir Square was the frequent site of often large occupations and sit-ins. In such cases, precise counts would normally be reported. When they were not, and given the size of Tahrir, occupations and sit-ins were coded as 1001.

3. Repertoire: The type of protest. This was normally contained within the protest report itself or could be identified in the videos or photos of the protests. Repertoire could be one of "demonstration" (manifestation/protestation or مظاهرة/احتجاج); "march" (marche or مسيرة); "strike" strike (grève or إضراب); "general strike" (grève régionale or إضراب عام محلي); "blockade" (bloquer la route or قطع الطرابقة); attack (attaque or مهاحمة); "occupation" (occupation or اعتصام) or "sit-in" (sit-in or وقفة احتجاجية).

4. Secondary repertoire: The secondary repertoire of the protest. Sometimes, protests or sit-ins would e.g. break out into marches along the surrounding streets. In such cases, a secondary repertoire would be recorded.

5. Protest location: The specific location of the protest e.g. outside Wilayat building or UGTT offices.

6. Starting location: A general identifier for the start location. One of "city centre"; "govt building" (e.g. any official building such as police station, local government building, RCD or NDP (ruling party) offices); "factory/public utility"; "hospital"; "main road"; 
"public transport" (e.g. railway/bus station); "residential street"; "saha (Tunisia) or midan (Egypt)" (square); "mosque"; "school" or "university".

7. Moving to: Where the protest moved to, if it did move.

8. End location: General identifier for where the protest ended, from among those listed above.

9. Organizer: Organizer of the protest. This was coded for both those specifically identified as organizing the protest e.g. "unionists" in Tunisia were normally from the national trade union federation the UGTT while in Egypt protests might be called by a specific activist group e.g. "Kefaya". Otherwise, organizer was coded for the principal participants e.g. "teachers" or "students" or "workers".

10. Activists: Binary variable coded " 1 " if organizer included activists.

11. Labour: Binary variable coded "1" if organizer included workers or unionists or if repertoire was strike.

12. Residents: Binary variable coded "1" if organizer included local residents.

13. Students: Binary variable coded " 1 " if organizer included students.

\section{A.4 Appendix - residual plots}

Below, Figures A.3 and A.4 provide residuals plots for the Egypt and Tunisia event data. As we note in the main text, tests of model fit indicate that negative binomial regression should be preferred. The top panel plots fitted values against those observed in our data. The y-axis shows standardized residuals (denominated by st. dev.). The majority of residuals should fall between \pm 2 standard deviations, which they do for both countries. The second panel provides a half-normal plot for our negative binomial models (see Atkinson 1981). ${ }^{14}$. This method simulates confidence intervals (envelopes) to provide a visual goodness of fit test. The residual deviance of the negative binomial model in both the Egypt and Tunisia data is greater than the residual degrees of freedom but residuals track closely to the simulated envelope though with some larger deviance for a small number of observations. The influence plot in the bottom panel displays the same information as panel (a) in another way: residuals are indexed by day and here we see that the largest residuals occur during periods of particularly intense mobilization. These deviations should be expected - numerous contributions point to the heavy-tailed distribution of protest data (Biggs 2016). Following Hilbe (2011), we employ robust standard errors in all of our analyses.

${ }^{14}$ To compute these, we use the hnp package in $\mathrm{R}$ developed by Moral and colleagues (2017) 
Figure A.3: Residuals diagnostics Egypt

(a) Residuals plots

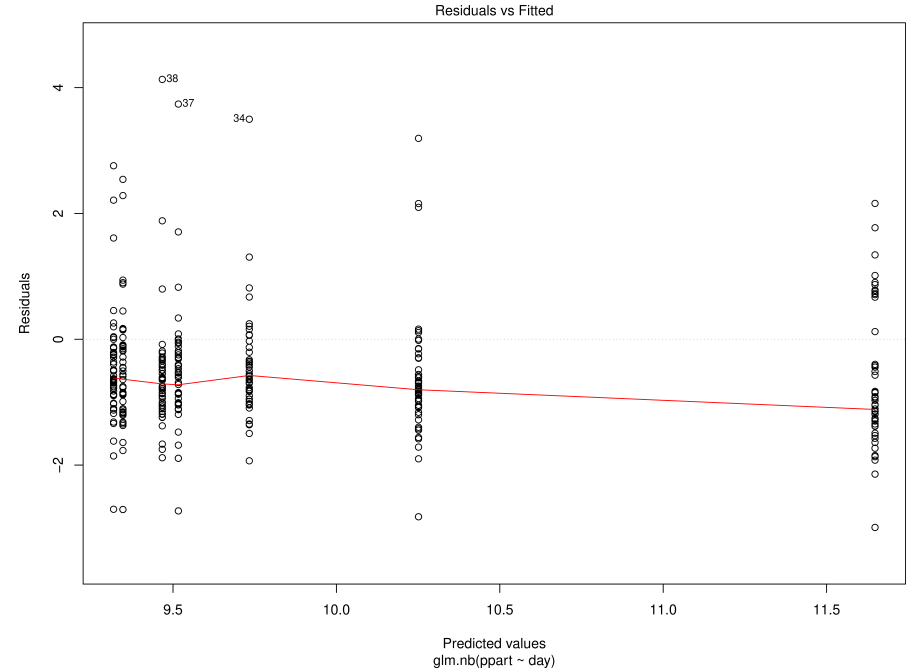

(b) Half-normal plot

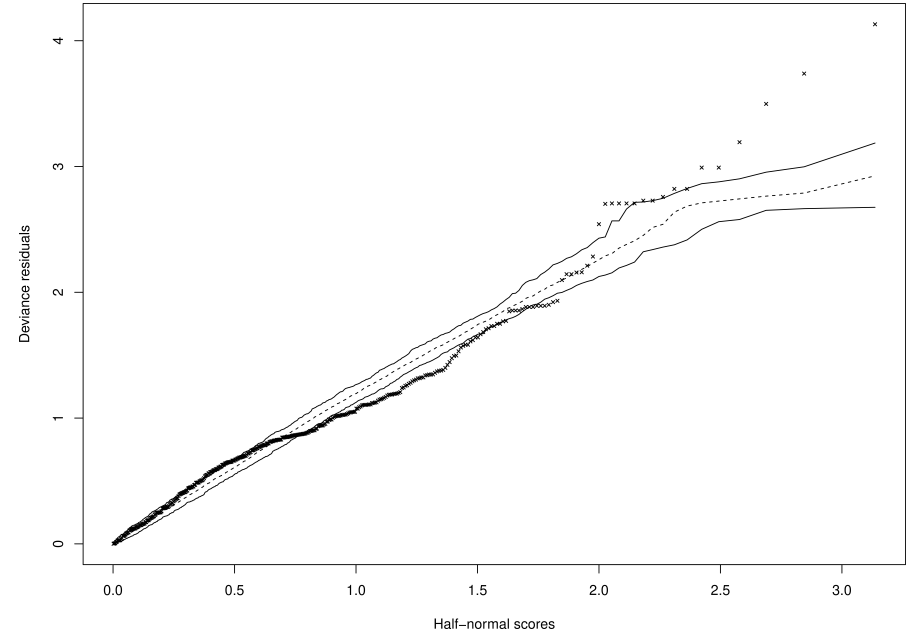

(c) Influence plot. Note: indexed by day (1-365) Influence plot

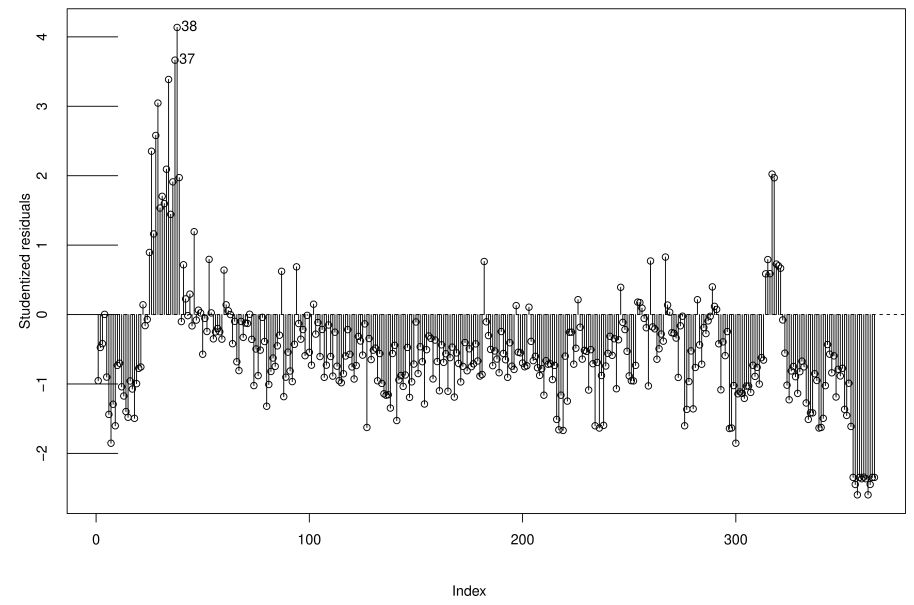


Figure A.4: Residuals diagnostics Tunisia

(a) Residuals plots

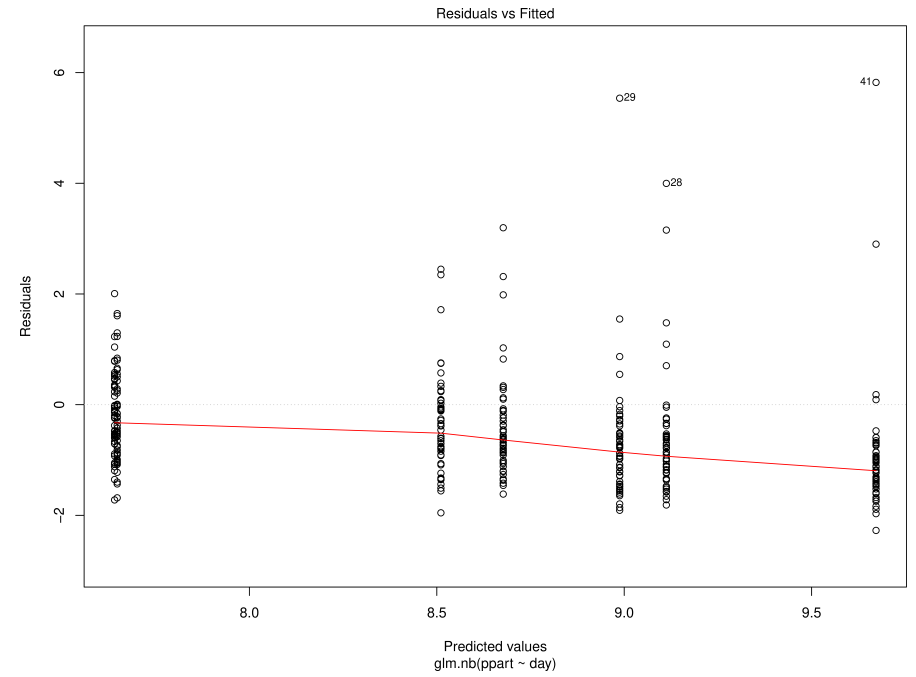

(b) Half-normal plot

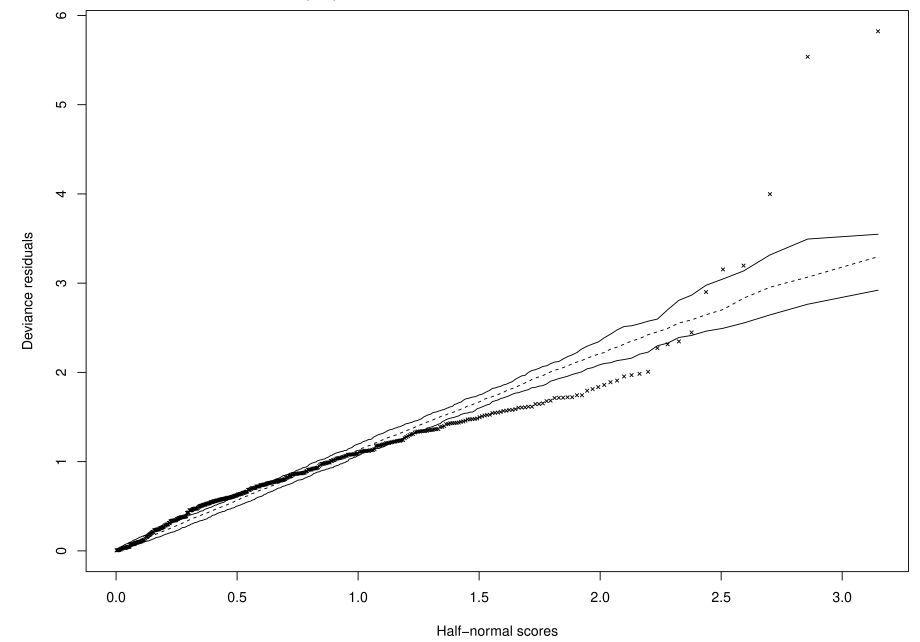

(c) Influence plot. Note: indexed by day (1-380) Influence plot

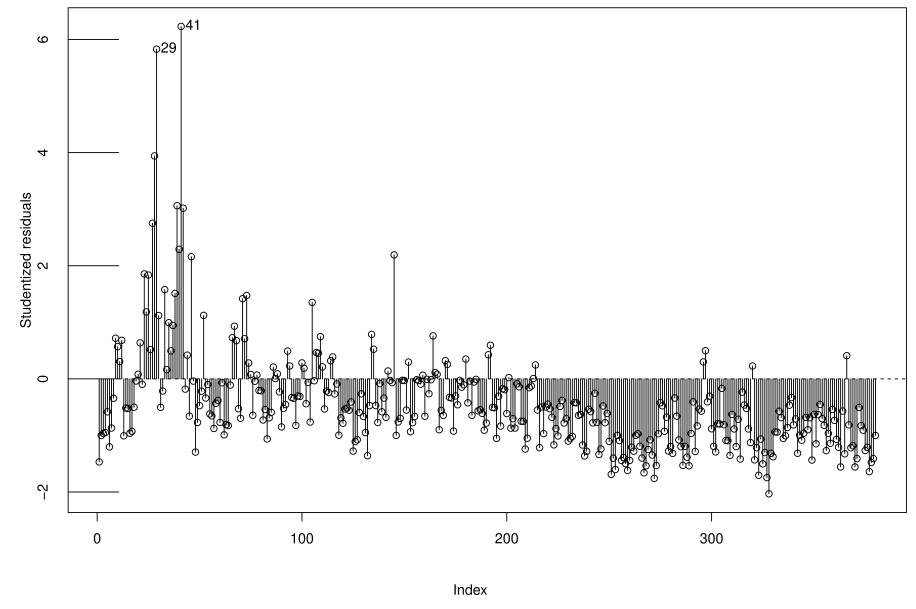




\section{A.5 Appendix - additional analyses}

Table A.1: Seemingly unrelated estimation: Egypt and Tunisia Friday protest participation.

\begin{tabular}{|c|c|}
\hline & Model 1: Egypt versus Tunisia \\
\hline Friday dummy & $\begin{array}{c}1.987^{* * *} \\
(0.335)\end{array}$ \\
\hline lnalpha & $\begin{array}{c}1.065^{* * *} \\
(0.077)\end{array}$ \\
\hline Friday dummy & $\begin{array}{c}0.187 \\
(0.619)\end{array}$ \\
\hline lnalpha & $\begin{array}{c}0.704^{* * *} \\
(0.151)\end{array}$ \\
\hline non-Friday & \\
\hline
\end{tabular}

In Table ?? we directly compare the average size of Friday protest in Tunisia with Egypt. To do this we re-estimate the negative binomial models shown in Figures 3 and 5. To enable direct comparability, we enter the total population for each country as the exposure term and a dummy variable for Fridays. The results are as expected. Friday protest in Egypt was significantly and substantially larger than protest held on days that were not Friday $(\mathrm{p}<.001)$. In Tunisia, protest participation on Friday was not greater than on non-Fridays $(p=.76)$. A pairwise comparison of coefficients suggests that the difference between the two cases is itself statistically significantly different from zero $(\mathrm{p}<.001)$.

Table A.2: Logistic regression: Tunisia gender interaction for participation in transitional period.

\begin{tabular}{lc}
\hline \hline & Model 1 \\
\hline Female $=1$ & -0.698 \\
& $(0.358)$ \\
Tunisia $=1$ & $1.355^{* * *}$ \\
& $(0.240)$ \\
& \\
Female*Tunisia & -0.424 \\
& $(0.423)$ \\
\hline \hline Standard errors in parentheses \\
${ }^{*} p<0.05,{ }^{* *} p<0.01,{ }^{* * *} p<0.001$
\end{tabular}

In Table A.2, we explore whether the reliance on a focal day of protest in Egypt had an effect on the gender composition of revolutionary crowds. Given the predominance of males at Friday prayer, we may expect to see men more likely to protest in Egypt when compared to Tunisia; a country where we did not see such a reliance on Fridays as focal points. Wave II of 
Table A.3: Logistic regression: Tunisia gender interaction for participation in transitional protests and controlling for previous revolutionary participation.

\begin{tabular}{lc}
\hline \hline & Model 1 \\
\hline Female $=1$ & -0.075 \\
& $(0.381)$ \\
Tunisia $=1$ & $0.983^{* * *}$ \\
& $(0.263)$ \\
& -0.220 \\
Female*Tunisia & $(0.452)$ \\
& \\
Revolution participation & $3.084^{* * *}$ \\
& $(0.207)$ \\
\hline \hline Standard errors in parentheses \\
${ }^{*} p<0.05,{ }^{* *} p<0.01,{ }^{* * *} p<0.001$
\end{tabular}

the Arab Barometer contains a question for participation in protest in the post-revolutionary period in both countries. Logistic regression suggests that males were significantly more likely to join protest in both Egypt and Tunisia, indicating that the gender composition of protestors was not directly related to the importance of Fridays or the mobilizing role of mosques. We demonstrate this by pooling survey respondents and introducing an interaction term between Tunisia and gender. Results indicate no significant difference in protest participants in the transition as the coefficient on this interaction term is not statistically significant. Interestingly, however, in both countries the importance of gender goes away after controlling for whether a respondent participated in the 25 January Revolution or protests against the Ben Ali regime. This is shown in Table A.3. Put differently, the "who" of protest during the transition is, in part, predicted by the preceding anti-systemic mobilization. This cannot be attributed to multicollinearity as the correlation between participation in the revolution and participation in protests during the subsequent transitional period is modest at .46. This underscores the importance of those precipitating events in patterning the dynamics of contention in the post-revolutionary aftermath.

\section{A.6 Appendix - full regression outputs}


Table A.4: Protest participation by sector: Egypt. Negative binomial regression with Sunday as reference day.

\begin{tabular}{lcccc}
\hline \hline & Mod. 1: students & Mod. 2: residents & Mod. 3: activists & Mod. 4: labour \\
\hline Monday & $-1.059^{*}$ & -0.418 & -0.241 & $-0.471^{*}$ \\
& $(0.506)$ & $(0.444)$ & $(0.522)$ & $(0.235)$ \\
Tuesday & -0.340 & 0.159 & 1.108 & -0.051 \\
& $(0.511)$ & $(0.468)$ & $(0.827)$ & $(0.335)$ \\
Wednesday & -0.325 & -0.610 & -1.208 & -0.205 \\
& $(0.561)$ & $(0.462)$ & $(0.804)$ & $(0.314)$ \\
Thursday & $-1.344^{*}$ & -0.689 & & -0.149 \\
& $(0.566)$ & $(0.437)$ & $(1.062)$ & $(0.442)$ \\
Friday & $-1.235^{*}$ & 0.190 & $3.732^{* * *}$ & $-1.178^{* *}$ \\
& $(0.560)$ & $(0.494)$ & $(0.712)$ & $(0.377)$ \\
Saturday & -1.031 & -0.226 & 0.549 & -0.098 \\
& $(0.575)$ & $(0.557)$ & $(0.848)$ & $(0.313)$ \\
\hline Ref. day & Sunday & Sunday & Sunday & Sunday \\
\hline \hline
\end{tabular}

Standard errors in parentheses

${ }^{*} p<0.05,{ }^{* *} p<0.01,{ }^{* * *} p<0.001$

Table A.5: Protest participation by location: Egypt. Negative binomial regression with Sunday as reference day.

\begin{tabular}{lcccc}
\hline \hline & Mod. 1: workplace & Mod. 2: campus & Mod. 3: pub. space & Mod. 4: worship \\
\hline Monday & -0.452 & $-0.854^{*}$ & -0.372 & $-2.334^{* *}$ \\
& $(0.315)$ & $(0.431)$ & $(0.757)$ & $(0.759)$ \\
Tuesday & -0.192 & -0.185 & 0.734 & 1.281 \\
& $(0.408)$ & $(0.557)$ & $(0.896)$ & $(0.853)$ \\
Wednesday & -0.173 & -0.545 & -0.136 & -0.919 \\
& $(0.409)$ & $(0.484)$ & $(0.990)$ & $(1.052)$ \\
Thursday & -0.100 & $-1.392^{* *}$ & -0.115 & -0.783 \\
& $(0.638)$ & $(0.474)$ & $(0.985)$ & $(1.024)$ \\
Friday & $-1.285^{* *}$ & $-1.865^{* *}$ & $2.273^{* *}$ & $3.384^{* * *}$ \\
& $(0.468)$ & $(0.569)$ & $(0.756)$ & $(0.789)$ \\
Saturday & -0.031 & $-1.507^{* *}$ & -0.533 & -0.279 \\
& $(0.389)$ & $(0.492)$ & $(0.652)$ & $(0.797)$ \\
\hline Ref. day & Sunday & Sunday & Sunday & Sunday \\
\hline \hline Standard errors in parentheses & & & \\
$* 0.05,{ }^{* *} p<0.01,{ }^{* * *} p<0.001$ & & &
\end{tabular}


Table A.6: Protest participation by repertoire: Egypt. Negative binomial regression with Sunday as reference day.

\begin{tabular}{|c|c|c|c|c|}
\hline & Mod. 1: disruptive & Mod. 2: transitory & Mod. 3: economic & Mod. 4: static \\
\hline Monday & $\begin{array}{l}-0.190 \\
(0.297)\end{array}$ & $\begin{array}{l}-0.330 \\
(0.352)\end{array}$ & $\begin{array}{l}-0.544 \\
(0.334)\end{array}$ & $\begin{array}{l}-0.473 \\
(0.765)\end{array}$ \\
\hline Tuesday & $\begin{array}{l}-0.003 \\
(0.434)\end{array}$ & $\begin{array}{c}0.860 \\
(0.531)\end{array}$ & $\begin{array}{c}0.252 \\
(0.480)\end{array}$ & $\begin{array}{c}0.377 \\
(0.858)\end{array}$ \\
\hline Wednesday & $\begin{array}{l}-0.016 \\
(0.425)\end{array}$ & $\begin{array}{c}-0.744^{*} \\
(0.325)\end{array}$ & $\begin{array}{l}-0.482 \\
(0.442)\end{array}$ & $\begin{array}{c}0.004 \\
(0.930)\end{array}$ \\
\hline Thursday & $\begin{array}{l}-0.497 \\
(0.385)\end{array}$ & $\begin{array}{l}-0.607 \\
(0.556)\end{array}$ & $\begin{array}{c}0.008 \\
(0.659)\end{array}$ & $\begin{array}{l}-0.145 \\
(0.990)\end{array}$ \\
\hline Friday & $\begin{array}{c}0.615 \\
(0.585)\end{array}$ & $\begin{array}{c}2.887^{* * *} \\
(0.359)\end{array}$ & $\begin{array}{l}-1.277^{*} \\
(0.519)\end{array}$ & $\begin{array}{c}0.878 \\
(0.819)\end{array}$ \\
\hline Saturday & $\begin{array}{l}-0.487 \\
(0.331)\end{array}$ & $\begin{array}{c}0.095 \\
(0.398)\end{array}$ & $\begin{array}{l}-0.189 \\
(0.478)\end{array}$ & $\begin{array}{l}-0.800 \\
(0.619)\end{array}$ \\
\hline Ref. day & Sunday & Sunday & Sunday & Sunday \\
\hline
\end{tabular}

Standard errors in parentheses

${ }^{*} p<0.05,{ }^{* *} p<0.01,{ }^{* * *} p<0.001$

Table A.7: Protest participation by sector: Tunisia. Negative binomial regression with Monday as reference day.

\begin{tabular}{|c|c|c|c|c|}
\hline & Mod. 1: students & Mod. 2: residents & Mod. 3: activists & Mod. 4: labour \\
\hline Sunday & $\begin{array}{c}-3.341^{* * *} \\
(0.744)\end{array}$ & $\begin{array}{l}-1.548^{*} \\
(0.604)\end{array}$ & $\begin{array}{c}-2.019^{* *} \\
(0.635)\end{array}$ & $\begin{array}{c}-2.019^{* *} \\
(0.635)\end{array}$ \\
\hline Tuesday & $\begin{array}{l}-2.046^{*} \\
(0.804)\end{array}$ & $\begin{array}{l}-1.331^{*} \\
(0.556)\end{array}$ & $\begin{array}{c}0.486 \\
(0.618)\end{array}$ & $\begin{array}{c}0.486 \\
(0.618)\end{array}$ \\
\hline Wednesday & $\begin{array}{l}-0.203 \\
(0.975)\end{array}$ & $\begin{array}{c}-1.869^{* *} \\
(0.643)\end{array}$ & $\begin{array}{c}1.622 \\
(0.984)\end{array}$ & $\begin{array}{c}1.622 \\
(0.984)\end{array}$ \\
\hline Thursday & $\begin{array}{l}-1.457 \\
(0.997)\end{array}$ & $\begin{array}{l}-0.465 \\
(0.942)\end{array}$ & $\begin{array}{c}0.864 \\
(0.980)\end{array}$ & $\begin{array}{c}0.864 \\
(0.980)\end{array}$ \\
\hline Friday & $\begin{array}{l}-1.805^{*} \\
(0.901)\end{array}$ & $\begin{array}{c}-0.384 \\
(0.885)\end{array}$ & $\begin{array}{c}0.612 \\
(0.934)\end{array}$ & $\begin{array}{c}0.612 \\
(0.934)\end{array}$ \\
\hline Saturday & $\begin{array}{l}-1.557 \\
(0.910)\end{array}$ & $\begin{array}{c}-1.756^{* *} \\
(0.671)\end{array}$ & $\begin{array}{l}-1.034 \\
(0.719)\end{array}$ & $\begin{array}{l}-1.034 \\
(0.719)\end{array}$ \\
\hline Ref. day & Monday & Monday & Monday & Monday \\
\hline
\end{tabular}


Table A.8: Protest participation by location: Tunisia. Negative binomial regression with Monday as reference day.

\begin{tabular}{lcccc}
\hline \hline & Mod. 1: workplace & Mod. 2: campus & Mod. 3: pub. space & Mod. 4: trad. un. \\
\hline Sunday & -0.200 & $-3.129^{* * *}$ & -1.089 & -1.210 \\
Tuesday & $(0.199)$ & $(0.790)$ & $(0.631)$ & $(0.925)$ \\
& 0.448 & 0.030 & -0.586 & 0.275 \\
Wednesday & $(0.257)$ & $(1.050)$ & $(0.666)$ & $(0.954)$ \\
& 0.181 & 0.003 & 1.498 & 0.793 \\
Thursday & $(0.231)$ & $(0.917)$ & $(0.988)$ & $(1.101)$ \\
& 0.219 & -0.427 & 0.160 & 1.251 \\
Friday & $(0.245)$ & $(0.950)$ & $(0.784)$ & $(1.133)$ \\
& -0.103 & $-1.898^{*}$ & -0.146 & 2.065 \\
Saturday & $(0.192)$ & $(0.948)$ & $(0.707)$ & $(1.216)$ \\
& -0.227 & $-1.888^{*}$ & $-1.233^{*}$ & -1.217 \\
lnalpha & $(0.197)$ & $(0.857)$ & $(0.616)$ & $(0.981)$ \\
& $1.037^{* * *}$ & $3.655^{* * *}$ & $2.320^{* * *}$ & $3.762^{* * *}$ \\
\hline Ref. day & $(0.097)$ & $(0.123)$ & $(0.082)$ & $(0.123)$ \\
\hline \hline
\end{tabular}

Standard errors in parentheses

${ }^{*} p<0.05,{ }^{* *} p<0.01,{ }^{* * *} p<0.001$ 
Table A.9: Protest participation by repertoire: Tunisia. Negative binomial regression with Monday as reference day.

\begin{tabular}{lcccc}
\hline \hline & Mod. 1: disruptive & Mod. 2: transitory & Mod. 3: economic & Mod. 4: static \\
\hline Sunday & $-1.981^{* * *}$ & $-1.066^{*}$ & $-1.284^{* * *}$ & -0.194 \\
Tuesday & $(0.456)$ & $(0.418)$ & $(0.368)$ & $(0.157)$ \\
& $-1.282^{*}$ & -0.519 & & 0.097 \\
Wednesday & $(0.549)$ & $(0.503)$ & $(0.339)$ & 0.115 \\
& -1.016 & 1.290 & -0.095 & -0.104 \\
Thursday & $(0.558)$ & $(0.899)$ & $(0.403)$ & $(0.204)$ \\
& -0.909 & 0.436 & & -0.088 \\
Friday & $(0.573)$ & $(0.641)$ & $(0.452)$ & $(0.208)$ \\
& -0.524 & 0.726 & $-0.867^{*}$ & 0.313 \\
Saturday & $(0.689)$ & $(0.820)$ & $(0.432)$ & $(0.387)$ \\
& $-1.487^{* *}$ & -1.055 & $-1.406^{* * *}$ & -0.340 \\
\hline Ref. day & $(0.472)$ & $(0.555)$ & $(0.355)$ & $(0.208)$ \\
\hline \hline
\end{tabular}

Standard errors in parentheses

${ }^{*} p<0.05,{ }^{* *} p<0.01,{ }^{* * *} p<0.001$ 